\title{
Sporadic aurorae observed in East Asia
}

\author{
D. M. Willis ${ }^{1,2}$, F. R. Stephenson ${ }^{3}$, and Huiping Fang ${ }^{1}$ \\ ${ }^{1}$ Centre for Fusion, Space and Astrophysics, Department of Physics, University of Warwick, Coventry CV4 7AL, UK \\ ${ }^{2}$ Rutherford Appleton Laboratory, Chilton, Didcot, Oxon OX11 0QX, UK \\ ${ }^{3}$ Department of East Asian Studies, University of Durham, Durham DH1 3TH, UK
}

Received: 1 August 2006 - Revised: 14 November 2006 - Accepted: 23 January 2007 - Published: 8 March 2007

\begin{abstract}
All the accessible auroral observations recorded in Chinese and Japanese histories during the interval AD 18401911 are investigated in detail. Most of these auroral records have never been translated into a Western language before. The East Asian auroral reports provide information on the date and approximate location of each auroral observation, together with limited scientific information on the characteristics of the auroral luminosity such as colour, duration, extent, position in the sky and approximate time of occurrence. The full translations of the original Chinese and Japanese auroral records are presented in an appendix, which contains bibliographic details of the various historical sources. (There are no known reliable Korean observations during this interval.) A second appendix discusses a few implausible "auroral" records, which have been rejected. The salient scientific properties of all exactly dated and reliable East Asian auroral observations in the interval AD 1840-1911 are summarised succinctly. By comparing the relevant scientific information on exactly dated auroral observations with the lists of great geomagnetic storms compiled by the Royal Greenwich Observatory, and also the tabulated values of the $A k$ (Helsinki) and $a a$ (Greenwich and Melbourne) magnetic indices, it is found that 5 of the great geomagnetic storms ( $a a>150$ or $A k>50$ ) during either the second half of the nineteenth century or the first decade of the twentieth century are clearly identified by extensive auroral displays observed in China or Japan. Indeed, two of these great storms produced auroral displays observed in both countries on the same night. Conversely, at least $29(69 \%)$ of the 42 Chinese and Japanese auroral observations occurred at times of weak-to-moderate geomagnetic activity ( $a a$ or $A k \leq 50$ ). It is shown that these latter auroral displays are very similar to the more numerous (about 50) examples of sporadic aurorae observed in the United States during the interval AD 1880-1940. The lo-
\end{abstract}

Correspondence to: D. M. Willis

(d.m.willis@rl.ac.uk) calised nature and spatial structure of some sporadic aurorae observed in East Asia is indicated by the use of descriptive terms such as "lightning", "rainbow", "streak" and "grid".

Keywords. Ionosphere (Auroral ionosphere) - Magnetospheric physics (Auroral phenomena; Storms and substorms)

\section{Introduction}

The occurrence of the aurora borealis or aurora australis at relatively low geomagnetic latitudes during periods of weakto-moderate geomagnetic activity has been reported in the literature on rare occasions. A salient feature of these reports is that the aurora was observed at geomagnetic latitudes that would conventionally imply the concurrent existence of a great geomagnetic storm. Botley (1963) drew attention to this phenomenon and used the term "sporadic aurora", which she adopted from the earlier paper by Abbe (1895). In particular, Botley (1963) defined sporadic aurorae as "comprising such instances as a single ray in a sky otherwise seemingly clear of auroral light, or isolated patches well to the equatorial side of a great display". Moreover, she noted a casual mention by Fritz (1881) of observations in low geomagnetic latitudes when there was apparently little incidence of the aurora in high latitudes. Within the context of auroral physics, the word "sporadic" often has the connotation of a "spatially isolated" region of the night sky. Therefore, the term "sporadic aurorae" may be used to describe localised auroral displays that occur at low geomagnetic latitudes (approximately, $-45^{\circ} \leq$ geomagnetic latitude $\leq+45^{\circ}$ ) during intervals of weak-to-moderate geomagnetic activity $(a a \leq 50)$. The converse situation ("non-sporadic aurorae") is the more familiar one in which extensive auroral displays at low geomagnetic latitudes occur at the times of great geomagnetic

Published by Copernicus GmbH on behalf of the European Geosciences Union. 
storms and hence during intervals of strong geomagnetic activity $(a a>150)$.

Silverman (2003) stated that he had originally discounted the early reports of sporadic aurorae but had been forced to re-evaluate the situation after he found a number of similar records in a compilation of data from the United States. Indeed, Silverman (2003) provided the first proper scientific study of the existence of sporadic (or localised) auroral observations at relatively low latitudes, during periods of weak-to-moderate geomagnetic activity, by tabulating some 54 cases of such sporadic auroral occurrence. Apart from one observation from Grahamstown, South Africa, all his examples of sporadic aurorae are from the United States and occurred during the interval AD 1880-1940. The sporadic auroral observations presented by Silverman (2003) were taken primarily from a database he compiled that is based largely on the series entitled "Climatological Data of the United States". Some additional observations were taken from other sources, principally the "Monthly Weather Review".

As noted by Silverman (2003), the only two previous papers that specifically discuss sporadic aurorae have reported a sufficiently small number of cases (Abbe, 1895, cites two and Botley, 1963, cites nine) to justify initial doubt about the reality of the phenomenon. From the historical viewpoint, the limited early evidence for sporadic aurorae may be summarised briefly as follows. Eddie (1894) presented an isolated example of such an event observed in the Southern Hemisphere, from Grahamstown, South Africa (geographic co-ordinates $33^{\circ} 19^{\prime} \mathrm{S}, 26^{\circ} 32^{\prime} \mathrm{E}$ ), on 1894 July 9 during a period of moderate geomagnetic activity (half-daily values of the $a a$ index during the interval July 7-10: 6, 9, 32, $37,25,26,8,9)$. Abbe (1895) published a description of an aurora on 1895 August 26, which was observed from both Charleston, South Carolina (geographic co-ordinates $32^{\circ} 48^{\prime} \mathrm{N}, 79^{\circ} 58^{\prime} \mathrm{W}$ ), and Greendale, Kentucky (geographic co-ordinates $38^{\circ} 06^{\prime} \mathrm{N}, 84^{\circ} 32^{\prime} \mathrm{W}$ ), during a period of weak geomagnetic activity (half-daily values of the $a a$ index during the interval August 24-27: 5, 8, 3, 4, 15, 9, 4, 5). Silverman (2003) quotes part of the text of the record from Grahamstown and the full text of the record from Charleston (which are both discussed in Sect. 3.2). Although Botley (1963) purportedly described nine such cases of sporadic aurorae, several of which may be classified as "doubtful" by the criteria presented by Silverman (2003), most of these cases actually occurred at times of strong geomagnetic activity.

The main purpose of this paper is to point out that some of the auroral observations recorded in Chinese and Japanese histories provide evidence for the occurrence of sporadic aurorae in another region of the world. To achieve this goal, every accessible and exactly dated (year, month and day all known precisely) oriental auroral observation that lies within the interval AD 1840-1911 has been extracted from the database of East Asian auroral observations discussed by Willis et al. (2005). However, three minor changes have been made to this database for the purposes of the present investi- gation; these changes are defined in Sect. 2. The first exactly dated and reliable East Asian auroral observation in this time interval was recorded in China on 1844 April 21 and the last was recorded in Japan on 1909 September 25 and 26 (the former day being the date of a great geomagnetic storm). The present study is deliberately restricted to the interval 1840 1911, so that direct comparisons can be made with the lists of great and small geomagnetic storms (1840-1954), compiled by the Royal Greenwich Observatory (1955), as well as with the magnetic indices $A k(1844-1867)$ and $a a(1868$ - present), discussed by Nevanlinna and Kataja (1993) and Mayaud (1980), respectively. Prior to 1840 , there are no proper quantitative measurements of geomagnetic activity that can be utilised in direct comparisons with the historical East Asian auroral observations, compilations of which do not extend beyond 1911. After 1911, lists of East Asian auroral sightings do not begin again until about the time of the International Geophysical Year (1957).

Therefore, the present investigation augments the study of sporadic auroral occurrence in the United States (Silverman, 2003) by identifying the occurrence of the same phenomenon in China and Japan. (There appear to be no reliable Korean auroral observations during the selected interval.) The approach adopted here differs slightly from that employed by Silverman (2003), at least to the extent that East Asian auroral observations coincident with great geomagnetic storms are not automatically eliminated from the investigation. Such observations are retained because they confirm the general reliability of the East Asian auroral observations (1840-1911), which might otherwise be considered to be intrinsically less reliable than the more recent auroral observations from the United States (1880-1940). Hence the approach adopted here is similar to that of Botley (1963), who presented auroral observations acquired at times of both strong and weak geomagnetic activity.

\section{The East Asian auroral observations}

The 1198 entries originally included in the auroral database compiled by Willis et al. (2005) are largely derived from the catalogue of auroral observations from China, Korea and Japan (193 BC-AD 1770) published by Yau et al. (1995). The material from this catalogue has been supplemented with additional data from several sources, notably: (1) Chinese auroral records included in the catalogue published (in Chinese) by the Beijing Observatory (1988), which extends the Chinese auroral observations back to at least $210 \mathrm{BC}$ and up to AD 1911; (2) the list of Japanese auroral records since AD 1600 included in the catalogue published (in Japanese) by Osaki (1994); and (3) a research paper by Matsushita (1956) on ancient aurorae seen in Japan. Three minor amendments have been made to the original auroral database compiled by Willis et al. (2005). First, the supposed Japanese "auroral" observation on AD 1850 August 15 has now 
been rejected because the quoted double hour shen (15:0017:00 LT) corresponds to late afternoon, which is long before sunset in August. Second, the supposed Chinese "auroral" observation on AD 1885 December 26 has now been rejected because the description of the phenomenon is obscure and does not necessarily correspond to an auroral display (despite the fact that it is included in the list compiled by the Beijing Observatory, 1988). Third, it has subsequently become clear that the extensive Japanese auroral observations on AD 1872 February 4 were followed by similar observations (also in Japan) on February 6. All the East Asian auroral observations within the interval AD 1840-1911 have been carefully translated into English, with appropriate help from experts in Classical Chinese and Japanese. The translations of the relevant records are presented in Appendix A. The reasons for rejecting the "auroral" observations on AD 1850 August 15 and AD 1885 December 26 are discussed in slightly more detail in Appendix B, which also includes a detailed discussion of the reasons for rejecting a potential Korean "auroral" observation on AD 1843 March 12.

It should be noted that the auroral catalogue published by the Beijing Observatory (1988) is divided into two parts: the second part is entitled "Not Definite Category". Although not strictly germane to this paper, a similar statement applies to the sunspot catalogue published by the Beijing Observatory (1988). It appears that the compilers of the Beijing catalogues have put entries in the "not definite category" if: (i) the date is very general; (ii) the content of the record is unclear; or (iii) the record is cited indirectly from some unavailable or unidentifiable source. Moreover, in the specific case of auroral observations (ji guang), entries seem to be included in the "not definite category" if there is any uncertainty whatsoever about the identification of an auroral display; for example, reference to a "black vapour like a rainbow", "glittering lights - like lightning" or a "dim light in the sky like a rainbow". In this paper, all Chinese auroral records extracted from the "not definite category" are identified by placing an asterisk after a chronological reference number (e.g. Ref. No. $01 *$ ), which is introduced later in this section.

The combined auroral catalogue that results from all these sources currently contains 1154 entries in the interval 210 BC-AD 1911 (although there are no exactly dated auroral observations in 1910 and 1911). However, the associated auroral database currently contains 1197 entries. The discrepancy between the number of entries in the catalogue and database arises partly from the fact that independent auroral observations (e.g. from different countries) are always included as separate entries in the auroral database and partly from the avoidance of auroral date ranges. In particular, auroral observations on consecutive days, which are sometimes included as a single entry in an auroral catalogue, are always included as separate entries in the auroral database. The paper by Willis et al. (2005) provides further details on the auroral database. As in this earlier paper, the present study is restricted to auroral records from East Asia for which the year, month and day are all specified exactly. This restriction is essential if meaningful comparisons are to be made with daily values of the $A k$ or $a a$ index and also the dates on which great and small geomagnetic storms occurred. Therefore, imprecise records, with inexact dates for which no more than the lunar month is specified, are automatically excluded from this investigation (cf. Willis et al., 2005).

Table 1 lists all the accessible and exactly dated Chinese and Japanese auroral observations that occurred during the interval 1840-1911 (apart from the two rejected records - see Appendix B). To facilitate cross-referencing between the tables and the text, a chronological reference number (Ref. No.) is provided in the first column of each entry in Table 1. Subsequent columns give the exact Gregorian date (year, month, day) of each auroral observation, as well as details of the place at which each observation was made, namely the country, the city, district or province/prefecture (with the present-day capital in parentheses), and the associated geographic and magnetic coordinates. All of the Chinese auroral observations presented in Table 1 and Appendix A have been gleaned from local histories or gazetteers. In most cases, only the provinces in which the observations were made have been recorded (see Appendix A). However, as investigation of reports of other celestial events - such as eclipses and meteors - clearly reveals, local histories are concerned with specific provinces. Duplication between histories of separate provinces is extremely rare. Hence it is appropriate to cite the geographic and magnetic co-ordinates of the relevant provincial capital - see Table 1. Although the provincial Chinese auroral observations may have been made at unknown locations outside the present-day capitals, the differences should amount to no more than a very few degrees in both latitude and longitude. Such differences are insignificant in this study. For the Japanese auroral observations, both specific locations and prefectures are quoted; the geographic and magnetic coordinates listed in Table 1 refer to the present-day capitals of the prefectures.

If an auroral display was observed from two or more locations in the same country on the same night (e.g. Shanghai Municipality \& Zhejiang Province (China) in 1866; Hamada Town \& Shimane Prefecture (Japan) in 1872), the co-ordinates listed apply to the first location specified in column 4 of Table 1. However, in all cases the co-ordinates of the other locations are cited either elsewhere in Table 1 or in the accompanying footnotes.

The geographic co-ordinates of all locations have been extracted from the Index in "The Times Comprehensive Atlas of the World" (1999); moreover, the spelling of place names follows that used in this index (apart from Seoul). It is clear from the entries in Table 1 (including the footnotes) that the geographic latitudes of the locations at which aurorae were observed in East Asia (i.e. the locations of the observers) during the interval 1840-1911 vary between about 
Table 1. Exactly dated Chinese and Japanese auroral observations recorded during the interval AD 1840-1911. After a chronological reference number (Ref. No.), introduced to facilitate cross-referencing, the exact Gregorian date of each auroral observation is given, followed by the country and then the city, district or province/prefecture of the place of observation (see Appendix A for further details). An asterisk $(*)$ qualifies the reference number if the associated Chinese auroral observation is from the "not definite category" (Beijing Observatory, 1988), rather than the "definite category", as discussed in Sect. 2. If the auroral observation was made in a Chinese province or Japanese prefecture, the present-day capital of that province or prefecture is given in parentheses. Also listed are the geographic co-ordinates (G. Lat., G. Long.) and magnetic co-ordinates (M. Lat., M. Long.) of each location or present-day capital. If a Chinese or Japanese auroral display was observed from two or more locations on the same night (e.g. Zhejiang \& Shanghai and Akita, Niigata \& Hokkaidō), the geographic, and hence magnetic, co-ordinates apply to the first location (although the co-ordinates of the other locations usually appear elsewhere in this table; otherwise, they are given in the footnote). The magnetic co-ordinates are corrected geomagnetic co-ordinates for epoch AD 1900 (see Sect. 2).

\begin{tabular}{|c|c|c|c|c|c|c|c|}
\hline Ref. No. & Date (Gregorian) & Country & City, District or Province/Prefecture (Capital) & G. Lat. $\left({ }^{\circ} \mathrm{N}\right)$ & G. Long. $\left({ }^{\circ} \mathrm{E}\right)$ & M. Lat. $\left({ }^{\circ} \mathrm{N}\right)$ & M. Long. $\left({ }^{\circ} \mathrm{E}\right)$ \\
\hline $01 *$ & 1844 Apr 21 & China & Hunan (Changsha) & $28^{\circ} 10^{\prime}$ & $112^{\circ} 59^{\prime}$ & $21^{\circ} 26^{\prime}$ & $181^{\circ} 36^{\prime}$ \\
\hline 02 & 1845 Mar 22 & Japan & Kyōto? & $34^{\circ} 59^{\prime}$ & $135^{\circ} 46^{\prime}$ & $28^{\circ} 28^{\prime}$ & $204^{\circ} 03^{\prime}$ \\
\hline $03 *$ & 1849 Jun 2 & China & Jiangsu (Nanjing) & $32^{\circ} 04^{\prime}$ & $118^{\circ} 50^{\prime}$ & $25^{\circ} 37^{\prime}$ & $187^{\circ} 29^{\prime}$ \\
\hline $04 *$ & $1853 \mathrm{Feb} 27$ & China & Shanxi (Taiyuan) & $37^{\circ} 48^{\prime}$ & $112^{\circ} 38^{\prime}$ & $31^{\circ} 35^{\prime}$ & $181^{\circ} 20^{\prime}$ \\
\hline 05 & 1853 Apr 23 & China & Shaanxi (Xi'an) & $34^{\circ} 12^{\prime}$ & $108^{\circ} 59^{\prime}$ & $27^{\circ} 46^{\prime}$ & $177^{\circ} 39^{\prime}$ \\
\hline $06 *$ & $1853 \mathrm{Jul} 12$ & China & Hubei (Wuhan) & $30^{\circ} 37^{\prime}$ & $114^{\circ} 18^{\prime}$ & $24^{\circ} 04^{\prime}$ & $182^{\circ} 56^{\prime}$ \\
\hline $07 *$ & 1853 Aug 12 & China & Sichuan (Chengdu) & $30^{\circ} 43^{\prime}$ & $104^{\circ} 04^{\prime}$ & $23^{\circ} 58^{\prime}$ & $172^{\circ} 44^{\prime}$ \\
\hline 08 & 1855 Aug 23 & Japan & Tōkyō & $35^{\circ} 41^{\prime}$ & $139^{\circ} 48^{\prime}$ & $29^{\circ} 07^{\prime}$ & $207^{\circ} 49^{\prime}$ \\
\hline 09 & 1856 Aug 18 & China & Guizhou (Guiyang) & $26^{\circ} 33^{\prime}$ & $106^{\circ} 39^{\prime}$ & $19^{\circ} 32^{\prime}$ & $175^{\circ} 18^{\prime}$ \\
\hline 10 & 1856 Aug 19 & China & Guizhou (Guiyang) & $26^{\circ} 33^{\prime}$ & $106^{\circ} 39^{\prime}$ & $19^{\circ} 32^{\prime}$ & $175^{\circ} 18^{\prime}$ \\
\hline 11 & 1859 Mar 2 & China & Hubei (Wuhan) & $30^{\circ} 37^{\prime}$ & $114^{\circ} 18^{\prime}$ & $24^{\circ} 04^{\prime}$ & $182^{\circ} 56^{\prime}$ \\
\hline 12 & 1859 Aug 4 & China & Henan (Zhengzhou) & $34^{\circ} 41^{\prime}$ & $113^{\circ} 41^{\prime}$ & $28^{\circ} 20^{\prime}$ & $182^{\circ} 22^{\prime}$ \\
\hline 13 & 1859 Sep 2 & China & Hebei (Shijiazhuang) & $38^{\circ} 00^{\prime}$ & $114^{\circ} 30^{\prime}$ & $31^{\circ} 47^{\prime}$ & $183^{\circ} 13^{\prime}$ \\
\hline 14 & 1859 Sep 2 & Japan & Shingū & $33^{\circ} 43^{\prime}$ & $136^{\circ} 00^{\prime}$ & $27^{\circ} 11^{\prime}$ & $204^{\circ} 16^{\prime}$ \\
\hline 15 & $1861 \mathrm{Jul} 23$ & China & Sichuan (Chengdu) & $30^{\circ} 43^{\prime}$ & $104^{\circ} 04^{\prime}$ & $23^{\circ} 58^{\prime}$ & $172^{\circ} 44^{\prime}$ \\
\hline 16 & 1862 Jan 1 & China & Sichuan (Chengdu) & $30^{\circ} 43^{\prime}$ & $104^{\circ} 04^{\prime}$ & $23^{\circ} 58^{\prime}$ & $172^{\circ} 44^{\prime}$ \\
\hline 17 & $1862 \mathrm{Jul} 29$ & China & Shanghai Municipality & $31^{\circ} 14^{\prime}$ & $121^{\circ} 30^{\prime}$ & $24^{\circ} 46^{\prime}$ & $190^{\circ} 07^{\prime}$ \\
\hline 18 & 1863 Jan 4 & China & Guangdong (Guangzhou) & $23^{\circ} 09^{\prime}$ & $113^{\circ} 21^{\prime}$ & $16^{\circ} 03^{\prime}$ & $181^{\circ} 56^{\prime}$ \\
\hline $19 *$ & $1863 \mathrm{Feb} 18$ & China & Hebei (Shijiazhuang) & $38^{\circ} 00^{\prime}$ & $114^{\circ} 30^{\prime}$ & $31^{\circ} 47^{\prime}$ & $183^{\circ} 13^{\prime}$ \\
\hline $20^{*}$ & 1866 Aug 27 & China & Zhejiang (Hangzhou) \& Shanghai Mun. & $30^{\circ} 15^{\prime}$ & $120^{\circ} 10^{\prime}$ & $23^{\circ} 44^{\prime}$ & $188^{\circ} 47^{\prime}$ \\
\hline 21 & 1866 Nov 5 & China & Hunan (Changsha) & $28^{\circ} 10^{\prime}$ & $112^{\circ} 59^{\prime}$ & $21^{\circ} 26^{\prime}$ & $181^{\circ} 36^{\prime}$ \\
\hline 22 & $1868 \mathrm{Jul} 6$ & Japan & Tōkyō & $35^{\circ} 41^{\prime}$ & $139^{\circ} 48^{\prime}$ & $29^{\circ} 07^{\prime}$ & $207^{\circ} 49^{\prime}$ \\
\hline 23 & $1869 \mathrm{Jul} 25$ & China & Hubei (Wuhan) & $30^{\circ} 37^{\prime}$ & $114^{\circ} 18^{\prime}$ & $24^{\circ} 04^{\prime}$ & $182^{\circ} 56^{\prime}$ \\
\hline 24 & $1870 \mathrm{Feb} 25$ & China & Jiangxi (Nanchang) & $28^{\circ} 42^{\prime}$ & $115^{\circ} 58^{\prime}$ & $22^{\circ} 03^{\prime}$ & $184^{\circ} 34^{\prime}$ \\
\hline 25 & $1871 \mathrm{Feb} 16$ & China & Shanxi (Taiyuan) & $37^{\circ} 48^{\prime}$ & $112^{\circ} 38^{\prime}$ & $31^{\circ} 35^{\prime}$ & $181^{\circ} 20^{\prime}$ \\
\hline 26 & 1871 Sep 17 & China & Guangdong (Guangzhou) & $23^{\circ} 09^{\prime}$ & $113^{\circ} 21^{\prime}$ & $16^{\circ} 03^{\prime}$ & $181^{\circ} 56^{\prime}$ \\
\hline 27 & 1872 Jan 10 & China & Shaanxi (Xi'an) & $34^{\circ} 12^{\prime}$ & $108^{\circ} 59^{\prime}$ & $27^{\circ} 46^{\prime}$ & $177^{\circ} 39^{\prime}$ \\
\hline 28 & 1872 Jan 11 & China & Shanxi (Taiyuan) & $37^{\circ} 48^{\prime}$ & $112^{\circ} 38^{\prime}$ & $31^{\circ} 35^{\prime}$ & $181^{\circ} 20^{\prime}$ \\
\hline 29 & $1872 \mathrm{Feb} 4$ & China & Hebei (Shijiazhuang) \& Hubei (Wuhan) & $38^{\circ} 00^{\prime}$ & $114^{\circ} 30^{\prime}$ & $31^{\circ} 47^{\prime}$ & $183^{\circ} 13^{\prime}$ \\
\hline 30 & 1872 Feb 4 & Japan & Hamada \& Shimane (Matsue) ${ }^{\mathrm{a}}$ & $34^{\circ} 53^{\prime}$ & $132^{\circ} 04^{\prime}$ & $28^{\circ} 25^{\prime}$ & $200^{\circ} 32^{\prime}$ \\
\hline 31 & 1872 Feb 5 & China & Hubei (Wuhan) & $30^{\circ} 37^{\prime}$ & $114^{\circ} 18^{\prime}$ & $24^{\circ} 04^{\prime}$ & $182^{\circ} 56^{\prime}$ \\
\hline 32 & 1872 Feb 6 & Japan & Shizuoka (Hamamatsu) ${ }^{\mathrm{b}} \&$ Shimane & $34^{\circ} 42^{\prime}$ & $137^{\circ} 44^{\prime}$ & $28^{\circ} 09^{\prime}$ & $205^{\circ} 54^{\prime}$ \\
\hline 33 & 1872 Jun 20 & China & Guangdong (Guangzhou) & $23^{\circ} 09^{\prime}$ & $113^{\circ} 21^{\prime}$ & $16^{\circ} 03^{\prime}$ & $181^{\circ} 56^{\prime}$ \\
\hline $34 *$ & 1872 Nov 30 & China & Jiangsu (Nanjing) & $32^{\circ} 04^{\prime}$ & $118^{\circ} 50^{\prime}$ & $25^{\circ} 37^{\prime}$ & $187^{\circ} 29^{\prime}$ \\
\hline 35 & 1873 Jan 24 & China & Shaanxi (Xi'an) & $34^{\circ} 12^{\prime}$ & $108^{\circ} 59^{\prime}$ & $27^{\circ} 46^{\prime}$ & $177^{\circ} 39^{\prime}$ \\
\hline 36 & $1897 \mathrm{Feb} 1$ & China & Guangdong (Guangzhou) & $23^{\circ} 09^{\prime}$ & $113^{\circ} 21^{\prime}$ & $16^{\circ} 03^{\prime}$ & $181^{\circ} 56^{\prime}$ \\
\hline 37 & 1899 Apr 8 & China & Guangdong (Guangzhou) & $23^{\circ} 09^{\prime}$ & $113^{\circ} 21^{\prime}$ & $16^{\circ} 03^{\prime}$ & $181^{\circ} 56^{\prime}$ \\
\hline 38 & 1900 Jan 30 & China & Anhui (Hefei) & $31^{\circ} 51^{\prime}$ & $117^{\circ} 19^{\prime}$ & $25^{\circ} 23^{\prime}$ & $185^{\circ} 58^{\prime}$ \\
\hline 39 & 1905 Jan 16 & China & Shanghai City & $31^{\circ} 14^{\prime}$ & $121^{\circ} 30^{\prime}$ & $24^{\circ} 46^{\prime}$ & $190^{\circ} 07^{\prime}$ \\
\hline 40 & $1908 \mathrm{Jul} 12$ & China & Shaanxi (Xi'an) & $34^{\circ} 12^{\prime}$ & $108^{\circ} 59^{\prime}$ & $27^{\circ} 46^{\prime}$ & $177^{\circ} 39^{\prime}$ \\
\hline 41 & 1909 Sep 25 & Japan & Akita (Akita), Niigata \& Hokkaidō ${ }^{\mathrm{c}}$ & $39^{\circ} 43^{\prime}$ & $140^{\circ} 07^{\prime}$ & $33^{\circ} 10^{\prime}$ & $208^{\circ} 03^{\prime}$ \\
\hline 42 & 1909 Sep 26 & Japan & Niigata (Niigata), Akita \& Hokkaidō ${ }^{\mathrm{c}}$ & $37^{\circ} 55^{\prime}$ & $139^{\circ} 03^{\prime}$ & $31^{\circ} 22^{\prime}$ & $207^{\circ} 06^{\prime}$ \\
\hline
\end{tabular}

Notes: ${ }^{\mathrm{a}}$ The geographic and geomagnetic co-ordinates of Matsue, the present-day capital of the Shimane Prefecture, are $35^{\circ} 28^{\prime} \mathrm{N}, 133^{\circ} 03^{\prime} \mathrm{E}$ and $28^{\circ} 59^{\prime} \mathrm{N}, 201^{\circ} 28^{\prime} \mathrm{E}$, respectively. ${ }^{\mathrm{b}}$ The geographic and geomagnetic co-ordinates of Hamamatsu, which is in the western part of the Shizuoka Prefecture, are supposed to define the location of the last of the four Japanese auroral observations on this particular date (see Appendix A, Ref. No. 32, Record iv). ${ }^{\mathrm{c}}$ The geographic and geomagnetic co-ordinates of Sapporo, the present-day capital of the Hokkaidō Prefecture, are $43^{\circ} 04^{\prime} \mathrm{N}, 141^{\circ} 20^{\prime} \mathrm{E}$ and $36^{\circ} 31^{\prime} \mathrm{N}, 209^{\circ} 02^{\prime} \mathrm{E}$, respectively. 
$23^{\circ} \mathrm{N}$ and $43^{\circ} \mathrm{N}$. The associated magnetic latitudes and longitudes are corrected geomagnetic co-ordinates at the Earth's surface. These magnetic co-ordinates have been obtained using the Geomagnetic Reference Field for Epoch AD 1900 (i.e. using DGRF/IGRF for 1900) in the Space Physics Data Facility/Modelweb software provided by the Goddard Space Flight Center (http://modelweb.gsfc.nasa.gov). In this study, it has been assumed that it is marginally preferable to include the higher harmonics of the geomagnetic reference field at a fixed epoch (AD 1900), rather than use just the dipole components at each of the actual times of the auroral observations in the interval 1840-1911. It is clear from Table 1 that the corrected geomagnetic latitudes of the locations at which aurorae were observed in East Asia vary between about $16^{\circ} \mathrm{N}$ and $37^{\circ} \mathrm{N}$.

The translations of the East Asian auroral records listed in Table 1 are presented in Appendix A, which provides a complete historical reference for all but one of these records. Most of these auroral records (some of which are rather terse and stereotyped by modern scientific standards) have not previously been translated into English or any other Western language. However, the importance of the descriptions of the oriental displays is enhanced by the fact that the great majority of the records of sporadic auroral events listed by Silverman (2003) merely report an observation on a particular date at a known location. The records included in the series entitled "Climatological Data of the United States" do not provide descriptions, although some descriptions may still exist in various national data archives in the United States. In Sect. 3.3, the descriptions of sporadic aurorae observed in East Asia are compared with the two descriptions of sporadic aurorae presented by Silverman (2003); namely the one from Grahamstown, South Africa, and the one from Charleston, South Carolina. In general, however, the information recorded in East Asian histories is inadequate to determine the height of the auroral display above the horizon (or even whether or not it was overhead).

\section{Scientific interpretation of the observations}

Table 2 contains a succinct summary of the scientific content of each of the East Asian auroral records listed in Table 1. For completeness, the date of the oriental observation is repeated in Table 2 but the country of origin is now denoted simply by a capital letter in parentheses $(\mathrm{C}=$ China, $\mathrm{J}$ = Japan). The time of occurrence, colour(s), compass position(s) and spatial extent(s) of each auroral observation have been extracted from the translations of the East Asian records presented in Appendix A. Table 2 also indicates whether or not ("Yes", "No") a great geomagnetic storm was in progress at the time of each auroral observation, according to the lists of geomagnetic storms (both great and small) published by the Royal Greenwich Observatory (1955). In addition, daily values of the $A k$ (Helsinki) magnetic index (before 1868) and the $a a$ magnetic index (from 1868) are presented for a sevenday interval centred on the day (date) of the East Asian auroral observation (Mayaud, 1973, 1980; Nevanlinna and Ketola, 1993; Nevanlinna et al., 1993; Nevanlinna and Kataja, 1993). To achieve consistency between the numerical accuracies of the tabulated $A k$ and $a a$ indices, daily values of the $a a$ index have been rounded to the nearest integer. The final column of Table 2 (entitled "Comments") serves to emphasise the dates of both great and small geomagnetic storms and also those occasions when there was clearly defined spatial structure in the auroral display, as inferred from the description in the auroral record (see Appendix A). For example, several records suggest structure by the use of terms such as "lightning" (dian), "rainbow" (hong), "streak" (dao) and "grid" (jing). (In one instance, the term "rainbow" is abbreviated to $\mathrm{R}$ in Table 2.)

Detailed lists of both great and small geomagnetic storms (based on Greenwich data up to the end of 1925 and Abinger data since the beginning of 1926) are available for the interval 1874-1954 and a list of great geomagnetic storms (based on Greenwich data) is available for the earlier interval 18401874 (Royal Greenwich Observatory, 1955). The lower limit of range for a great geomagnetic storm at Greenwich (or Abinger) was adopted as $60^{\prime}$ in declination $(D)$ or $300 \mathrm{nT}$ $(\gamma)$ in either the horizontal magnetic field $(H)$ or the vertical magnetic field $(Z)$. For small geomagnetic storms, the lower limit for inclusion is $30^{\prime}$ in $D$ or $150 \mathrm{nT}$ in $H$ or in $Z$. In the published tables, the ranges are given to the nearest minute of arc in $D$ and the nearest $5 \mathrm{nT}$ in $H$ and $Z$. (For completeness, it should be noted that the same limits apply to the period from 1916 to 1924 inclusive, when the north component of the geomagnetic field was recorded instead of the horizontal component.)

It is clear from Table 2 that about $25 \%$ of the East Asian auroral records refer to observations that occurred when a great geomagnetic storm was in progress (and hence invariably occurred under conditions of strong geomagnetic activity), whereas about $75 \%$ of the records refer to auroral observations that occurred when no great geomagnetic storm was in progress (and hence almost always occurred under conditions of weak-to-moderate geomagnetic activity). As noted in the Introduction, auroral observations coincident with great geomagnetic storms are retained in this study because they confirm the general reliability of the East Asian auroral observations in the interval 1840-1911. The oriental auroral observations are discussed separately in the two following subsections (3.1 and 3.2) for conditions of strong and weak-to-moderate geomagnetic activity. The two subsequent subsections (3.3 and 3.4) discuss the evidence for spatial structure in the descriptions of sporadic aurorae and the reliability of the East Asian auroral observations. 
Table 2. Scientific attributes of exactly dated East Asian auroral observations in the interval AD 1840-1911. The chronological reference number (Ref. No.) and associated date is exactly the same as in Table 1. For brevity, the country of origin of each observation is now denoted simply by a capital letter in parentheses $(\mathrm{C}=$ China, $\mathrm{J}=\mathrm{Japan}$ ). The scientific content of each oriental auroral observation is summarised briefly, with specific reference (whenever possible) to the time of occurrence, colour(s), compass position(s) and spatial extent (see Appendix A). The presence ("Yes"), or absence ("No"), of a great storm (RGO) implies inclusion in, or exclusion from, the lists of great geomagnetic storms compiled by the Royal Greenwich Observatory (1955). Daily values of the $A k$ index (before AD 1868) or the $a a$ index (from AD 1868) are presented for a 7-day interval centred on the day of the oriental auroral observation (values of the $a a$ index have been rounded to the nearest integer). In the "Comments" column, explicit reference is made to both great (Gt) and small (Sm) geomagnetic storms and also the existence of spatial structure in the auroral display, as inferred from the description recorded in the oriental history or gazetteer (see Appendix A).

\begin{tabular}{|c|c|c|c|c|c|c|c|c|c|c|c|}
\hline \multirow{2}{*}{$\begin{array}{l}\text { Ref. No. } \\
01 *\end{array}$} & \multirow{2}{*}{$\begin{array}{l}\text { Date of Aurora } \\
\text { (Country) }\end{array}$} & \multirow{2}{*}{$\begin{array}{l}\text { Time of occurrence, colour, } \\
\text { compass position and spatial extent } \\
\text { At dusk, in S, a light illuminated the } \\
\text { sky ( } \cong 2 \mathrm{~h})\end{array}$} & \multirow{2}{*}{$\begin{array}{l}\text { Great } \\
\text { Storm } \\
(\mathrm{RGO})\end{array}$} & \multicolumn{7}{|c|}{$\begin{array}{l}\text { Daily } A k \text { index or daily } a a \text { index } \\
(-3 \text { days to }+3 \text { days })\end{array}$} & \multirow[t]{2}{*}{ Comments } \\
\hline & & & & ND & ND & ND & ND & ND & ND & ND & \\
\hline 02 & $1845 \operatorname{Mar} 22(\mathrm{~J})$ & $\begin{array}{l}\text { White vapour in } \mathrm{Z} \text { (zenith or mid- } \\
\text { sky) }\end{array}$ & No & 28 & 23 & 17 & 11 & 21 & 26 & 40 & \\
\hline $03 *$ & 1849 Jun $2(\mathrm{C})$ & At night, the sky was red like blood & No & 5 & 4 & 10 & 23 & 14 & 11 & 19 & \\
\hline $04 *$ & 1853 Feb $27(\mathrm{C})$ & Yin $[03: 00-05: 00]$, the sky was red & No & 4 & 16 & 5 & 8 & 19 & 26 & 6 & \\
\hline 05 & 1853 Apr $23(\mathrm{C})$ & $\begin{array}{l}\text { Third watch [23:00-01:00], sky was } \\
\text { red like blood }\end{array}$ & No & 18 & 14 & 31 & 24 & 7 & 13 & 13 & \\
\hline $06^{*}$ & 1853 Jul $12(\mathrm{C})$ & $\begin{array}{l}X u[19: 00-21: 00], \text { Wh, Bl-Gr, Pu } \\
\text { streaks; } \mathrm{S} \rightarrow \mathrm{N}\end{array}$ & Yes & 6 & 12 & 33 & 51 & 53 & 11 & 12 & Great Storm: Jul 12-13 \\
\hline $07 *$ & 1853 Aug $12(\mathrm{C})$ & $\begin{array}{l}\text { Night, black vapour like a rainbow; } \\
\mathrm{W} \rightarrow \mathrm{E}\end{array}$ & No & 25 & 10 & 7 & 7 & 3 & 10 & 6 & Structure (Rainbow) \\
\hline 08 & 1855 Aug $23(\mathrm{~J})$ & $\begin{array}{l}\text { White vapour in } S \text {; bright at [21:00- } \\
23: 00] \text { on date }\end{array}$ & No & 17 & 10 & 9 & 6 & 19 & 6 & 9 & \\
\hline 09 & 1856 Aug $18(\mathrm{C})$ & $\begin{array}{l}\text { Midnight, blood-red rainbow hung } \\
\text { down in NW }\end{array}$ & No & ND & ND & ND & ND & ND & ND & ND & Structure (Rainbow) \\
\hline 10 & 1856 Aug $19(\mathrm{C})$ & $\begin{array}{l}\text { Night, blood-red rainbow drooped } \\
\text { down in NW }\end{array}$ & No & ND & ND & ND & ND & ND & ND & ND & Structure (Rainbow) \\
\hline 11 & $1859 \operatorname{Mar} 2(\mathrm{C})$ & $\begin{array}{l}\text { Night, red vapour in sky; divided } \\
\text { like a grid }\end{array}$ & No & 12 & 10 & 11 & 10 & 20 & 42 & 24 & Structure (Grid) \\
\hline 12 & 1859 Aug $4(\mathrm{C})$ & $\begin{array}{l}\text { Night, in the } \mathrm{N} \text { direction, sky was } \\
\text { red like fire }\end{array}$ & No & 4 & 5 & 5 & 4 & 4 & 5 & 4 & \\
\hline 13 & 1859 Sep $2(C)$ & $\begin{array}{l}\text { Night, red vapour rose in NW and } \\
\rightarrow \mathrm{NE}\end{array}$ & Yes & 13 & 22 & 35 & 32 & 58 & 75 & 51 & Great Storm: Sep 2-5 \\
\hline 14 & 1859 Sep $2(J)$ & $\begin{array}{l}\text { Night, [17:00-19:00] to } 24: 00 \text {, fire } \\
\text { disaster in N; red }\end{array}$ & Yes & 13 & 22 & 35 & 32 & 58 & 75 & 51 & Great Storm: Sep 2-5 \\
\hline 15 & $1861 \mathrm{Jul} 23$ (C) & $\begin{array}{l}\text { Middle of night, red fluttering ban- } \\
\text { ner in } \mathrm{Z}\end{array}$ & No & 34 & 16 & 9 & 15 & 8 & 41 & 12 & Structure (Fluttering Banner) \\
\hline 16 & 1862 Jan $1(\mathrm{C})$ & $\begin{array}{l}\text { Narrow split in sky; glittering lights } \\
\text { eventually conjoined }\end{array}$ & No & 5 & 2 & 6 & 19 & 22 & 8 & 3 & Structure (Narrow Split) \\
\hline 17 & 1862 Jul $29(\mathrm{C})$ & $\begin{array}{l}\text { Middle of night, sky suddenly be- } \\
\text { came bright as day }\end{array}$ & No & 17 & 16 & 24 & 23 & 12 & 11 & 7 & \\
\hline 18 & 1863 Jan $4(C)$ & $\begin{array}{l}\text { Middle of night, multicoloured } \\
\text { clouds appeared }\end{array}$ & No & 25 & 24 & 17 & 22 & 22 & 11 & 6 & \\
\hline $19 *$ & 1863 Feb $18(\mathrm{C})$ & Red vapour appeared in SE & No & 8 & 18 & 13 & 12 & 13 & 8 & 3 & \\
\hline $20 *$ & 1866 Aug $27(\mathrm{C})$ & $\begin{array}{l}\text { After nightfall, glittering lights in } \\
\text { SE; like lightning; } \mathrm{Pu}\end{array}$ & No & 56 & 16 & 13 & 23 & 18 & 5 & 21 & Structure (Lightning) \\
\hline 21 & 1866 Nov 5 (C) & $\begin{array}{l}\text { Middle of night, red light across sky; } \\
\text { like daylight }\end{array}$ & No & 55 & 46 & 42 & 10 & 26 & 19 & 23 & \\
\hline 22 & 1868 Jul $6(J)$ & $\begin{array}{l}\text { Midnight, two arcs extended from } \\
\mathrm{E} \rightarrow \mathrm{W}\end{array}$ & No & 10 & 27 & 18 & 18 & 10 & 18 & 37 & \\
\hline 23 & 1869 Jul 25 (C) & $\begin{array}{l}\text { Evening, blue-green rainbow, } \\
\mathrm{E} \rightarrow \mathrm{W} \text {; across half the sky }\end{array}$ & No & 17 & 14 & 5 & 13 & 25 & 9 & 9 & Structure (Rainbow) \\
\hline 24 & 1870 Feb $25(\mathrm{C})$ & $\begin{array}{l}\text { Night, red vapour appeared; divided } \\
\text { like a grid }\end{array}$ & No & 19 & 29 & 26 & 6 & 7 & 14 & 13 & Structure (Grid) \\
\hline 25 & 1871 Feb $16(C)$ & $\begin{array}{l}\text { Third watch [22:50-01:10], sky red; } \\
\text { as if Earth on fire }\end{array}$ & Yes & 51 & 19 & 19 & 21 & 14 & 5 & 3 & Gt Storm: Feb 11-13 \\
\hline
\end{tabular}


Table 2. Continued.

\begin{tabular}{|c|c|c|c|c|c|c|c|c|c|c|c|}
\hline \multirow{2}{*}{$\begin{array}{l}\text { Ref. No. } \\
26\end{array}$} & \multirow{2}{*}{$\begin{array}{l}\begin{array}{l}\text { Date of Aurora } \\
\text { (Country) }\end{array} \\
1871 \text { Sep } 17(\mathrm{C})\end{array}$} & \multirow{2}{*}{$\begin{array}{l}\text { Time of occurrence, colour, } \\
\text { compass position and spatial extent } \\
\text { Chou }[01: 00-03: 00], \mathrm{NE} \text {, streak of } \\
\text { red light; } \mathrm{Re}, \mathrm{Ye}, \mathrm{Gr}\end{array}$} & \multirow{2}{*}{$\begin{array}{l}\text { Great } \\
\text { Storm } \\
\text { (RGO) }\end{array}$} & \multicolumn{7}{|c|}{$\begin{array}{l}\text { Daily } A k \text { index or daily } a a \text { index } \\
(-3 \text { days to }+3 \text { days })\end{array}$} & \multirow{2}{*}{$\begin{array}{c}\text { Comments } \\
\text { Structure (Streak) }\end{array}$} \\
\hline & & & & 9 & 26 & 28 & 27 & 22 & 21 & 15 & \\
\hline 27 & 1872 Jan $10(C)$ & $\begin{array}{l}\text { Evening, sky split open; } S=\text { pale Ye } \\
\& N=R e\end{array}$ & No & 29 & 4 & 16 & 7 & 5 & 17 & 22 & \\
\hline 28 & 1872 Jan $11(\mathrm{C})$ & $\begin{array}{l}\text { Night }[01: 20-03: 50], \text { red light filled } \\
\text { sky; } \cong 2 \mathrm{~h})\end{array}$ & No & 4 & 16 & 7 & 5 & 17 & 22 & 25 & \\
\hline 29 & 1872 Feb $4(\mathrm{C})$ & $\begin{array}{l}\text { Night, from NE to SW, sky red like } \\
\text { fire, also red in NW }\end{array}$ & Yes & 41 & 14 & 12 & 230 & 54 & 22 & 16 & Gt Storm: Feb 4-5 \\
\hline 30 & 1872 Feb $4(\mathrm{~J})$ & $\begin{array}{l}\text { Night, in } \mathrm{N} \text {, sky was red like fire; } \\
\text { fire pillar in } \mathrm{N}\end{array}$ & Yes & 41 & 14 & 12 & 230 & 54 & 22 & 16 & Gt Storm: Feb 4-5 \\
\hline 31 & $1872 \mathrm{Feb} 5(\mathrm{C})$ & $\begin{array}{l}\text { Chou [01:00-03:00], red vapour } \\
\text { filled sky, } \uparrow \mathrm{NE} \rightarrow \mathrm{SW}^{\mathrm{a}}\end{array}$ & Yes & 14 & 12 & 230 & 54 & 22 & 16 & 16 & Gt Storm: Feb 4-5 \\
\hline 32 & $1872 \mathrm{Feb} 6(\mathrm{~J})$ & $\begin{array}{l}\text { Red sky like distant fire in E, NE \& } \\
\mathrm{N} \text {; fire pillar(s) in N }\end{array}$ & Yes & 12 & 230 & 54 & 22 & 16 & 16 & 10 & Gt Storm: Feb 4-5 \\
\hline 33 & 1872 Jun $20(C)$ & Night, red light filled the sky & No & 10 & 8 & 9 & 4 & 18 & 35 & 21 & \\
\hline $34 *$ & $1872 \operatorname{Nov} 30(\mathrm{C})$ & $\begin{array}{l}\text { Towards evening, dim light like } \\
\text { rainbow, } \mathrm{W} \rightarrow \mathrm{E}\end{array}$ & No & 29 & 12 & 16 & 15 & 8 & 14 & 20 & Structure (Rainbow) \\
\hline 35 & $1873 \operatorname{Jan} 24(\mathrm{C})$ & Night, the sky was red & No & 26 & 12 & 6 & 28 & 50 & 38 & 40 & \\
\hline 36 & $1897 \mathrm{Feb} 1(\mathrm{C})$ & $\begin{array}{l}X u[19: 00-21: 00], \text { red vapour in } \mathrm{SW} \\
(\sim 100 \text { chi wide })\end{array}$ & No & 15 & 13 & 10 & 9 & 4 & 21 & 30 & \\
\hline 37 & 1899 Apr $8(C)$ & $\begin{array}{l}\text { Night [before 01:30], red light emit- } \\
\text { ted from sky }\end{array}$ & No & 15 & 7 & 20 & 21 & 15 & 20 & 22 & \\
\hline 38 & 1900 Jan $30(C)$ & $\begin{array}{l}\text { Light like lightning, rising from } \\
\text { NW, shone like daylight }\end{array}$ & No & 13 & 11 & 6 & 3 & 5 & 4 & 6 & Structure (Lightning) \\
\hline 39 & $1905 \operatorname{Jan} 16(\mathrm{C})$ & $\begin{array}{l}\text { Midnight, red rainbow appeared, } \\
\mathrm{E} \rightarrow \mathrm{W} \text {; seen in N }\end{array}$ & No & 10 & 28 & 12 & 4 & 30 & 15 & 11 & Structure (Rainbow)) \\
\hline 40 & 1908 Jul $12(\mathrm{C})$ & $\begin{array}{l}\text { First watch [19:45-21:30], rainbow } \\
\text { extended } \mathrm{E} \rightarrow \mathrm{W}\end{array}$ & No & 6 & 4 & 5 & 10 & 10 & 5 & 28 & Sm Storm: Jul 15.6-17; R \\
\hline 41 & 1909 Sep $25(J)$ & $\begin{array}{l}\text { Night, seen in many areas; sketches } \\
\text { exist [23:30-00:55] }\end{array}$ & Yes & 15 & 10 & 6 & 329 & 23 & 16 & 26 & Great Storm: Sep 25.4 \\
\hline 42 & 1909 Sep $26(J)$ & $\begin{array}{l}\text { Night, seen in many areas; sketches } \\
\text { exist }[23: 30-00: 55]\end{array}$ & Yes & 10 & 6 & 329 & 23 & 16 & 26 & 15 & Great Storm: Sep 25.4 \\
\hline
\end{tabular}

Definitions: All quoted times and time intervals (e.g. Yin [04:00-05:00]) are expressed in local time (LT); N, NE, E, SE, S, SW, W, NW denote points of the compass; $\mathrm{Z}$ denotes the zenith; $\uparrow$ indicates "upwards" and $\rightarrow$ indicates "extension" (usually from one compass point to another); the abbreviations $\mathrm{Bl}=$ Blue, $\mathrm{Gr}=\mathrm{Green}, \mathrm{Pu}=$ Purple, $\mathrm{Re}=\mathrm{Red}$, Wh $=$ White, Ye $=$ Yellow are used to specify the colours of auroral displays; ${ }^{a}$ Ref. No. 31 also states "within the cloud there was one star like a bowl; its colour was blue"; ND signifies that no data (Ak) exist for that particular day; $\mathrm{R}=$ Rainbow (which necessarily implies "Structure" when used alone for brevity, as in the case of the Chinese auroral observation on AD 1908 July 12).

3.1 East Asian auroral observations during great geomagnetic storms

The entries in the final column of Table 2 indicate that two of the greatest geomagnetic storms of the nineteenth century, namely those on 1859 September 2-5 (Ref. Nos. 13 and 14) and 1872 February 4-5 (Ref. Nos. 29-32), are identified by auroral observations from both China and Japan. The date ranges of these two great geomagnetic storms (and other storms cited in Table 2) are taken directly from the lists of great and small storms recorded at Greenwich (Royal Greenwich Observatory, 1955). Moreover, the second of these two storms is associated with auroral observations in China on the nights of February 4 and 5 (Ref. Nos. 29 and 31) and auroral observations in Japan on the nights of February 4 and 6 (Ref. Nos. 30 and 32). The daily values of the $A k$ (Helsinki) magnetic index for the seven-day interval centred on the great geomagnetic storm of 1859 September 2 are as follows: 13, $22,35,32,58,75,51$ (although it seems likely that these values of the $A k$ index underestimate the true strength of this great geomagnetic storm). Likewise, the daily values of the $a a$ magnetic index for the seven-day interval centred on the great geomagnetic storm of 1872 February 4 are as follows (to the nearest integer value): $41,14,12,230,54,22,16$. The great geomagnetic storm of 1853 July $12-13$ is identified by an auroral observation from China on July 12 (Ref. No. 06*). The values of the $A k$ index for the seven-day interval centred on July 12 are as follows: 6, 12, 33, 51, 53, 11, 12 . It is also just possible that the great geomagnetic storm of 1871 February $11-13$ is associated with an auroral observation from China on February 16 (Ref. No. 25). The values of the $a a$ index for the seven-day interval centred on February 
16 are as follows: $51,19,19,21,14,5,3$; the corresponding values on the two previous days - February 11 and February 12 - are 50 and 158 , respectively.

Similarly, one of the great geomagnetic storms of the first decade of the twentieth century, namely that on 1909 September 25.4, is identified by auroral observations from Japan on the nights of both September 25 and 26 (Ref. Nos. 41 and 42). More extensive low-latitude auroral observations associated with this great geomagnetic storm have been compiled and discussed by Silverman (1995). The daily values of the $a a$ index for the seven-day interval centred on September 25 are as follows: 15, 10, 6, 329, 23, 16, 26. Conversely, the small geomagnetic storm on 1908 July 15.6-17 is most unlikely to be associated with the Chinese auroral observation on July 12 (Ref. No. 40) because in this case the auroral observation preceded the geomagnetic storm by three days.

Of course, there is no exact one-to-one correspondence between the great geomagnetic storms included in the lists compiled by the Royal Greenwich Observatory (1955) and auroral observations recorded in East Asia. Many potential auroral observations must have been missed as a result of extensive cloud cover (or other adverse viewing conditions), whereas the Royal Greenwich Observatory (RGO) lists of geomagnetic storms are based on magnetic measurements that are largely unaffected by the concurrent meteorological conditions. In particular, the RGO lists include 101 great geomagnetic storms in the interval 1840-1911 but only 5 of these storms appear in Table 2. The likely effects of cloud cover over East Asia can be estimated approximately by examining the global cloud cover maps that have been constructed using data acquired during the International Satellite Cloud Climatology Project (ISCCP). Since 1983, as part of ISCCP, visible and infrared images from polar orbiting and geostationary meteorological satellites have been processed to produce monthly data sets of global cloud cover and radiative properties (see, for example, http://www.gewex.org/ isccp.html). The maps of mean annual cloud amount indicate that the frequency of occurrence of cloudy conditions over East Asia in the interval 1983 (July) - 2005 (June) lies in the approximate range $50-80 \%$. Therefore, cloud cover can probably account for the fact that some of the great geomagnetic storms recorded at Greenwich in the interval 18401911 were not accompanied by auroral observations in East Asia. However, this provisional estimate of cloud cover over East Asia requires considerable further refinement within the context of auroral physics. For example, extensive auroral displays can be seen in the gaps between clouds (which may be less than the pixel size of the satellite images) and it also seems most unlikely that such displays would be completely obscured by thin cirrus cloud (which implies that cloud type is also an important factor). Despite these "meteorological" complications, the oriental auroral observations that are available correctly identify some of the really great geomagnetic storms that occurred during the second half of the nine- teenth century and the first decade of the twentieth century.

An extremely important feature of the East Asian auroral observations is that brief descriptions of the auroral displays have been recorded in the various histories. Although these descriptions are usually tantalisingly terse and somewhat stereotyped if judged by modern scientific standards, as noted in Sect. 2 they often provide some basic physical information on the structure of auroral displays observed under conditions of both strong and weak-to-moderate geomagnetic activity. Many of the auroral observations listed in Table 2 merely state that "the sky was red", or refer to a "red light" or a "red vapour" in the sky. Sometimes the colour "red" is qualified by such commonplace terms as "blood" or "fire". As is also clear from Table 2, the reference to a red sky is used for auroral displays that occur under conditions of both strong and weak-to-moderate geomagnetic activity. However, in the case of great geomagnetic storms, there is usually some mention of the large extent of the sky covered by the "red light" or "red vapour", often by reference to more than one point of the compass (Ref. Nos. 13, 14, 25, 29-32).

More detailed information is available for the great geomagnetic storm on 1853 July 12-13 (Ref. No. 06*), which is associated with one of the Chinese auroral observations somewhat surprisingly included in the "not definite category" (Beijing Observatory, 1988). For this particular storm, the description (see Appendix A) refers to "two streaks of white vapour"; the centre being "blue-green" while the lower part was "purple". One streak was "long" and the other was "short". The description also states that the streaks had "the form of a roll of silk gauze reaching straight to the zenith" and notes further that the aurora extended "from the $S$ to the N, gradually twisting to the W and disappearing". The level of detail provided in this particular auroral description is essentially comparable with that available from many contemporaneous European and North American auroral observations (e.g. Fritz, 1873; Loomis, 1859-1861; Silverman, 2006).

Although the descriptions of East Asian auroral observations during great geomagnetic storms usually indicate that the auroral display covered a large region of the sky, the descriptions of several of the East Asian sporadic auroral observations during weak-to-moderate geomagnetic activity suggest auroral structure over a more localised region of the sky, as discussed in the following subsection.

\subsection{East Asian observations of sporadic aurorae}

The detailed entries in Table 2 indicate that many of the East Asian auroral observations in the interval 1840-1911 occurred under conditions of weak-to-moderate geomagnetic activity. This conclusion is confirmed by relatively small values of the magnetic indices, $A k$ or $a a$, defined by Nevanlinna and Kataja (1993) and Mayaud (1980), respectively, or by the absence of a great geomagnetic storm ("No" in column 4 of Table 2) according to the lists of great geomagnetic storms 
compiled by the Royal Greenwich Observatory (1955). No values of the magnetic index $A k$ are available (ND) for three of the 42 auroral observations listed in Table 2 (i.e. Ref. Nos. 01*, 09 and 10). It then follows from column 4 of this table that $29(=74 \%)$ of the 39 East Asian auroral observations for which magnetic indices are available occurred at times when no great geomagnetic storm was in progress. Moreover, the daily magnetic index, $A k$ or $a a$, was $\leq 50$ throughout a five-day interval centred on the date of each of these 29 observations (including the auroral observation that occurred three days before the small geomagnetic storm on 1908 July 15.6-17). For a centred seven-day interval (as used in Sect. 3.1), the daily value of $A k$ or $a a$ slightly exceeded 50 for just two of the 203 daily observations ( $A k=56$ for Ref. No. 20* and $A k=55$ for Ref. No. 21). On both occasions, however, this excess occurred three days before the day (night) of the auroral observation (i.e. on Day - 3) and represented the nearest local maximum in the value of $A k$ immediately before the date of the auroral observation. For 12 $(=31 \%)$ of the 39 auroral observations for which daily magnetic indices are available, $A k$ or $a a \leq 25$ throughout a sevenday interval centred on the date of the auroral observation (Ref. Nos. 03*, 07*, 08, 12, 16, 17, 18, 19*, 23, 28, 37, 38). For comparison, $10(=26 \%)$ of the 39 auroral observations (for which magnetic indices are available) occurred at times when a great geomagnetic storm was in progress, although these particular auroral observations correspond to just 5 distinct geomagnetic storms.

For the Chinese auroral observation on 1859 August 4 (Ref. No. 12), $A k \leq 5$ throughout the seven-day interval centred on this date. Although it would be natural to question the reliability of any low-latitude auroral observation under such extremely weak, or quiet, geomagnetic conditions, it should be noted that the auroral observation on 1859 August 4 occurred 29 days before the commencement of the great geomagnetic storm on 1859 September 2-5. Actually, dual storms commenced on August 28 and September 2, both of which were accompanied by brilliant auroral displays seen from many parts of the world (Royal Greenwich Observatory, 1955; Silverman, 2006). Therefore, the auroral observation on August 4 occurred about one (mean) synodic-solarrotation period (27 days) before the dual storms on August 28 and September 2. The implication of this time sequence of events is that recurrent solar activity probably existed at this time, despite the apparently quiet geomagnetic conditions. In this same context, it should be noted that the Chinese auroral observations on 1853 February 27 (Ref. No. 04*) and 1853 April 23 (Ref. No. 05) occurred $135(=5 \times 27)$ days and 80 $(=3 \times 27-1)$ days, respectively, before the Chinese auroral observation on 1853 July 12 (Ref. No. $06^{*}$ ), which was the date of another great geomagnetic storm (1853 July 12-13). Likewise, it should be noted that the Chinese auroral observation on 1853 August 12 (Ref. No. $07^{*}$ ) occurred 30/31 days after this great geomagnetic storm. On all three days (apart from 1853 July 12 ), $A k \leq 31$ throughout a seven-day interval cen- tred on each of these dates. These Chinese auroral observations provide evidence for recurrent, albeit intermittent, auroral activity, on a timescale almost exactly equal to the mean synodic-solar-rotation period, before the great geomagnetic storm on 1853 July 12-13. Extensive cloud cover may have prevented a complete sequence of auroral observations separated by approximately 27 days. Finally, the Chinese auroral observations on 1872 January 10 and 11 (Ref. Nos. 27 and 28) occurred 25 days before the Chinese and Japanese auroral observations (Ref. Nos. 29-32) associated with the great geomagnetic storm on 1872 February 4-5.

It should be emphasised that some caution must be exercised when making comparisons between the magnetic index $A k$ (Nevanlinna and Kataja, 1993), which is based entirely on magnetic measurements at Helsinki, and unaidedeye auroral observations recorded in Chinese and Japanese histories. The difference in local time (LT) between Northern Europe and East Asia (ranging from about 5-9 h) may be significant for all but the most intense geomagnetic storms. Indeed, owing to the local-time variation of magnetic disturbances at Helsinki, the daily values of the $A k$ index cannot be compared with the daily values of the $a a$ index (Nevanlinna and Kataja, 1993). In addition, as noted in Sect. 3.1, the $A k$ index probably underestimates the true strength of even the great geomagnetic storm on 1859 September 2. Obviously, a similar cautionary remark applies to comparisons between magnetic measurements at Greenwich and auroral observations in East Asia. The magnetic index $a a$ (Mayaud, 1980), which is based on magnetic measurements at one observatory in England and one in Australia, is perhaps marginally better, if only because the magnetic observatory in Australia (Melbourne; geographic co-ordinates $37^{\circ} 49^{\prime} \mathrm{S}, 144^{\circ} 59^{\prime} \mathrm{E}$ ) is at approximately the same geographic longitude (and hence LT) as the locations of the East Asian auroral observations (see Table 1). Nevertheless, the magnetic indices $A k$ and $a a$ are not necessarily ideal for identifying magnetic disturbances that might be associated with sporadic aurorae in East Asia. In a similar vein, Kamide (2006) has noted that it is misleading to use the $D_{s t}$ magnetic index to define how much the entire solar-terrestrial system is disturbed.

\subsection{Evidence for spatial structure in descriptions of spo- radic aurorae}

Several of the descriptions of auroral observations included in Table 2 imply that structure was noted in the auroral luminosity. As noted previously, such structure is suggested by use of the terms "lightning", "rainbow", "streak" or "grid" (Ref. Nos. 06*, 07*, 09, 10, 11, 20*, 23, 24, 26, 34*, 38, $39,40)$. Other terms, like "fluttering banner" and "glittering lights", are much more problematic and could easily indicate temporal rather than spatial variations (Ref. Nos. 15, 16). One auroral observation (Ref. No. 20*) uses the terms "glittering lights" and "lightning", which may signify the concurrent existence of both spatial structure and temporal 
variations. Conversely, some of the descriptions of auroral observations made under weak-to-moderate geomagnetic activity $(a a \leq 50)$ suggest that essentially uniform auroral luminosity covered a substantial region of the sky (Ref. Nos. 02, $\left.03^{*}, 04^{*}, 05,08,12,17,19^{*}, 27,28,33,35,36,37\right)$, as in the case of great geomagnetic storms (Sect. 3.1). In this context, it should perhaps just be mentioned that the Chinese auroral observation on 1862 July 29 (Ref. No. 17) occurred six days before the great geomagnetic storm of August 4-5. Since different types of aurorae appear to occur under weak-to-moderate geomagnetic activity, it is difficult to offer a unique physical explanation. However, the use of the terms "lightning", "rainbow" or "streak" in some East Asian auroral records may signify a single ray of light in a sky otherwise seemingly clear of auroral luminosity, in accord with the definition of sporadic aurorae propounded by Botley (1963) and quoted by Silverman (2003). Moreover, the term "rainbow" probably implies both shape and colour and, as intimated previously, there is some evidence that the term "lightning" is used to emphasise the flickering nature of the light (Ref. No. 20*).

The detailed descriptions of the East Asian auroral observations presented in Appendix A, which are summarised succinctly in Table 2 (column 3 ), show some similarities to the descriptions of sporadic aurorae quoted by Silverman (2003). For example, the description of the aurora australis observed on 1894 July 9 (Eddie, 1894), from Grahamstown, South Africa, states that the display lasted from 21:15 LT to 23:15 LT (i.e. $2 \mathrm{~h}$ ). Despite bright moonlight (Moon at first quarter), this auroral display "manifested itself in a pale greenish white light extending around the south-eastern and southern horizon, and by broad streamers of a lovely roseate hue, which fitfully ebbed and flowed as they extended upwards from the south-east, at times right up to the zenith ..." Likewise, the aurora borealis observed on 1895 August 26 (Abbe, 1895), from Charleston, South Carolina, lasted from 22:47 LT to 22:58 LT (i.e. about $10 \mathrm{~min}$ ) and extended approximately from the NW to the N. As noted in the description, "a dark segment or arch rose to $17^{\circ}$, with a crown of light to $24^{\circ}$, one large streamer lasting from 22:51 LT to 22:53 LT (i.e. $2 \mathrm{~min}$ ); azimuth $116^{\circ}$ to $122^{\circ}$ (measured in the sense $\mathrm{S} \rightarrow \mathrm{W} \rightarrow \mathrm{N} \rightarrow \mathrm{E}$ ), and altitude $30^{\circ}$." This record also states "the display was accompanied by a thin veil of vapour, through which the stars could be seen." No detailed description is available for the display of the aurora borealis observed on 1876 May 20 (Fritz, 1873; Botley, 1963), from Canea, Crete (Chania, Kriti; geographic co-ordinates $\left.35^{\circ} 30^{\prime} \mathrm{N}, 24^{\circ} 02^{\prime} \mathrm{E}\right)$.

It is evident from the preceding descriptions that sporadic aurorae can last from several minutes to several hours. Although none of the East Asian auroral observations unambiguously implies a time interval as short as a few minutes, some of these observations suggest that the auroral display lasts for about one or two hours (Ref. Nos. 01*, 04*, 05, 25, $26,36,40)$. The descriptions of the auroral displays observed from Charleston and Grahamstown both refer to "streamers". Although the observation from Grahamstown actually refers to "broad streamers", there is a clear intimation of elongated rays (or streamers) in both cases. More specifically, the observation from Charleston suggests that one large streamer extended $6^{\circ}$ in azimuth and about $30^{\circ}$ in altitude, whereas the observation from Grahamstown suggests that the broad streamers extended over several multiples of $10^{\circ}$ in altitude (since at times they reached up to the zenith). This is in general agreement with the use of the terms "lightning", "rainbow" and "streak" in the East Asian auroral observations. Two of the East Asian auroral observations mention explicitly that the displays were either several tens of zhang (i.e. very many degrees) long, or several tens of zhang long and several chi (degrees) wide (see Ref. Nos. 07* and 16 in Appendix A).

None of the dates of the auroral observations from East Asia (1840-1911) in the absence of a great geomagnetic storm ("No" in column 4 of Table 2) coincides with the date of a sporadic aurora observed in the United States (18801940), as tabulated by Silverman (2003; see his Tables 1 and 2). A similar statement applies if the relevant East Asian auroral observations are compared with the sporadic aurorae observed from Canea, Crete, on AD 1876 May 20 (Botley, 1963) and from Grahamstown, South Africa, on 1894 July 9 (Eddie, 1894). The lack of any coincidences between East Asian auroral observations in the absence of a great geomagnetic storm and sporadic aurorae observed elsewhere in the world provides some, albeit limited, evidence for the truly localised nature of such auroral displays, although it should be emphasised that the East Asian observations were by no means systematic.

\subsection{Reliability of the East Asian auroral observations}

In the preceding discussion, it has been tacitly assumed that the East Asian auroral records listed in Tables 1 and 2 and presented in Appendix A are all equally reliable observations of the aurora borealis. Clearly, this assumption is not necessarily true. For example, the Japanese auroral observation on 1845 March 22 (Ref. No. 02) refers to a "white vapour" without stating explicitly that the observation was made during the night. In principle, it is at least possible that such a "white vapour" could have been seen during the daytime. Similarly, the detailed record of the Chinese auroral observation on 1862 January 1 (Ref. No. 16) does not state explicitly that the phenomenon was observed during the night, although judging from the description such an assumption seems entirely reasonable in this particular case. Likewise, the record of the Chinese auroral observation on 1863 February 18 (Ref. No. 19*) does not state explicitly that the phenomenon occurred at night, although the reference to a "red vapour" strongly supports the interpretation of the phenomenon as an auroral display. 
Conversely, the record of the Chinese auroral observation on 1853 April 23 (Ref. No. 05) states: "At the third watch of the night [23:00-01:00 LT], the sky was red like blood." In this instance, there is specific reference to the auroral display occurring at a particular time during the night, while the colour "red" is the one most commonly associated with low-latitude aurorae. It is known from modern observations that low-latitude aurorae are predominantly "red" in colour because they are typically characterised by: (i) $\mathrm{N}_{2}^{+} 1 \mathrm{~N}$ $(427.8 \mathrm{~nm})$ emission at high vibrational levels and (ii) a high $(>10)$ ratio of red $(630.0 \mathrm{~nm})$ to green $(557.7 \mathrm{~nm})$ atomic oxygen lines. An aurora of the second type sometimes produces intense visible emissions, which result in a spectacular red aurora in the night sky (Tinsley et al., 1984; Davis, 1992; Shiokawa et al., 2005). Other historical auroral records from East Asia are slightly more ambiguous. The record of the Chinese auroral observation on 1853 August 12 (Ref. No. $07^{*}$ ) indicates that the phenomenon was observed at night but states enigmatically: "there was a black (hei) vapour like a rainbow; it extended from the west to the east, several tens of zhang (i.e. very many degrees) in length." Regrettably, this Chinese record contains inadequate information for a completely reliable scientific interpretation, although it is tempting to speculate that this might be a genuine historical observation of a "black" aurora. A "black" aurora is a lack of auroral emission in a small, well-defined region (e.g. a beanshaped pod or a thin arc-like feature) within an otherwise uniform, diffuse background or within an aurora exhibiting a type of behaviour intermediate between that of "diffuse" aurora and "discrete" aurora (Davis, 1978, 1992; Newell et al., 2001).

In this context, however, it should be noted that all of the auroral observations which are clearly associated with great geomagnetic storms (Ref. Nos. 06*, 13, 14, 25, 2932,41 and 42) state explicitly that the observation was made during the "night" and all but two of these observations (Ref. Nos. 41 and 42) refer specifically either to the colour "red" or to a colour that is neither "white" nor "black" (see Ref. No. 06*). The Chinese record of the auroral observation on 1908 July 12 (Ref. No. 40), which occurred three days before a small (probably independent) geomagnetic storm (Royal Greenwich Observatory, 1955), notes that at the first watch of the night (19:45-21:30 LT) a rainbow extended from east to west and that after a while it began to disappear. This description is quite compatible with the occurrence of an auroral display and the use of the term "rainbow" suggests that the spatial extent of the auroral display is limited, which is consistent with the occurrence of a sporadic auroral observation.

In the case of the sporadic auroral observations from East Asia, the Chinese records for 1849 June 2, 1853 February 27, 1853 April 23, 1856 August 18, 1856 August 19, 1859 March 2, 1859 August 4, 1861 July 23, 1866 November 5, 1870 February 25, 1871 September 17, 1872 January 11, 1872 June 20, 1873 January 24, 1897 February 1, 1899 April
8 and 1905 January 16 (Ref. Nos. 03*, 04*, 05, 09, 10, 11, $12,15,21,24,26,28,33,35,36,37$ and 39) all state explicitly that the observation was made at "night" and refer to the colour "red". The Chinese record for 1872 January 10 (Ref. No. 27) indicates that the observation was made during the "evening" and refers to the colours "red" (in the N) and "pale yellow" (in the S). All of these 18 Chinese records appear to be quite genuine observations of the aurora borealis, which implies that at least $18(=43 \%)$ of the 42 auroral records from East Asia in the interval 1840-1911 describe sporadic auroral observations, in the sense that they are definitely not associated with one of the great geomagnetic storms included in the lists compiled by the Royal Greenwich Observatory (1955).

The Chinese record for 1863 January 4 (Ref. No. 18) states that "multicoloured clouds" appeared in the middle of the night and there seems little doubt that this is a reference to the aurora borealis. The Chinese record for 1869 July 25 (Ref. No. 23) refers to a "blue-green rainbow" extending across half the sky (E to $\mathrm{W}$ ) in the evening, which could also be a genuine observation of the aurora borealis. The Chinese record for 1908 July 12 (Ref. No. 40) notes that at the first watch (19:45-21:30 LT) a "rainbow" extended from east to west, which could again be a genuine observation of the aurora borealis (three days before the small geomagnetic storm on July 15.6-17). If these three additional Chinese records are accepted as being authentic observations of the aurora borealis not associated with a great geomagnetic storm, then 21 $(=50 \%)$ of the 42 auroral records from East Asia in the interval 1840-1911 refer to sporadic auroral observations. Conversely, only $10(=24 \%)$ of the 42 auroral observations from East Asia in this interval are definitely associated with great geomagnetic storms.

The six Chinese observations on 1844 April 21, $1853 \mathrm{Au}-$ gust 12, 1862 July 29, 1866 August 27, 1872 November 30 and 1900 January 30 (Ref. Nos. 01*, 07*, 17, 20*, 34* and 38) and the Japanese observation on 1855 August 23 (Ref. No. 08) either refer explicitly to the "dusk", "evening", "night" or else imply a night-time observation by use of the phrase "shone like daylight" (Ref. No. 38). Moreover, the wording used to describe each of these seven observations is largely compatible with the occurrence of an auroral display. The Japanese record for 1868 July 6 (Ref. No. 22) indicates that at midnight two arcs extended across the sky from east to west (Matsushita, 1956), which could be a genuine observation of the aurora borealis, despite the fact that Matsushita classified this observation as being "unlikely". Future identification of the original text may eventually clarify this matter (see Appendix A). If these eight additional observations are regarded as being authentic observations of the aurora borealis that are not associated with a great geomagnetic storm, then $29(=69 \%)$ of the 42 auroral records from East Asia in the interval 1840-1911 refer to sporadic auroral observations. 
It is now necessary to consider the three remaining observations. The Japanese observation on 1845 March 22 (Ref. No. 02) merely refers to a white vapour seen in the zenith (i.e. in mid-sky) at an unspecified time. The Chinese observation on 1862 January 1 (Ref. No. 16) refers to a split in the sky several tens of zhang (i.e. very many deg) in length and several chi (deg) in width and also glittering lights that eventually conjoined. This observation is not specifically stated to have occurred during the night, as noted previously, although in this particular case it is a reasonable inference. The Chinese observation on 1863 February 18 (Ref. No. 19*) simply states that a red vapour appeared at the SE. As also noted previously, there is again no mention of night but reference to the colour "red" suggests an auroral display. If these three further observations are provisionally accepted as genuine observations of the aurora borealis that are not associated with a great geomagnetic storm, then $32(=76 \%)$ of the 42 auroral records from East Asia in the interval 1840-1911 apparently refer to sporadic auroral observations.

Finally, a comment should perhaps be made on the relative merits of the East Asian auroral observations discussed in this paper and the observations from (mainly) the United States discussed in the paper by Silverman (2003). The available Chinese records of atmospheric phenomena during the period in question are virtually all from local histories. Unlike the reports in the astronomical treatises of the official histories, they are thus not based on systematic observation and their inclusion in local histories will to some extent reflect the interests of the compilers. However, it should be emphasised that the goal of this paper is to investigate aurorae that were observed in East Asia. This is a unique region with an unparalleled history of auroral (and other) observations extending back over two millennia. Moreover, as noted previously, although the auroral observations from East Asia (1840-1911) might initially be considered to be intrinsically less reliable than the more recent auroral observations from the United States (1880-1940), they have the added advantage that descriptions of the auroral displays are immediately available (see Appendix A), contrary to the situation for the great majority of the American observations of sporadic aurorae (Silverman, 2003).

\section{Discussion and conclusions}

The main purpose of this paper is to point out that a significant number of the auroral observations recorded in Chinese and Japanese histories during the interval AD 1840-1911 provide evidence for the occurrence of so-called "sporadic aurorae" in East Asia. This investigation therefore extends the work of Silverman (2003), who tabulated about 54 cases of such sporadic auroral occurrence from elsewhere in the world. Apart from one observation (Eddie, 1894) from Grahamstown, South Africa, all his examples of sporadic auroral occurrence are from the United States. The salient features of "sporadic" auroral observations are that they occur at rela- tively low latitudes (approximately, $-45^{\circ} \leq$ geomagnetic latitude $\leq+45^{\circ}$ ) during periods of weak-to-moderate geomagnetic activity ( $a a$ or $A k \leq 50$ ). Moreover, as observed from the surface of the Earth, they sometimes appear to be spatially localised in the night sky.

Table 1 lists all the accessible, exactly dated and reliable East Asian auroral observations in the interval AD 18401911, which have been extracted from the database of oriental auroral observations discussed by Willis et al. (2005). This table provides the Gregorian date of each auroral observation, the country, city, district or province/prefecture of the place at which the observation was made, as well as the geographic and magnetic co-ordinates of the place of observation. The translations of the oriental auroral records are presented in Appendix A and the reasons for rejecting three implausible "auroral" records are discussed in Appendix B. Table 2 summarises the scientific attributes of the exactly dated East Asian auroral observations, as inferred from the translated records, and indicates whether or not ("Yes", "No") a great geomagnetic storm was recorded at Greenwich on the same date. In addition, daily values of the $A k$ index (before $\mathrm{AD} 1868$ ) or the $a a$ index (from $\mathrm{AD} 1868$ ) are presented in Table 2 for a 7-day interval centred on the day of the oriental auroral observation.

Using the information presented in Table 2, it is possible to separate the exactly dated and reliable East Asian auroral observations in the interval AD 1840-1911 into two categories. The first category comprises those auroral observations that occurred in the presence of great geomagnetic storms ("Yes" in column 4) and hence occurred at times of strong geomagnetic activity ( $a a>150$ or $A k>50$ for at least one of the seven entries in column 5). The second category comprises those auroral observations that occurred in the absence of great geomagnetic storms ("No" in column 4) and at times of weakto-moderate geomagnetic activity ( $a a$ or $A k \leq 50$ for at least the central five entries in column 5). Observations in the second category are examples of sporadic aurorae recorded in East Asian histories. Moreover, the spatially localised nature of some of the oriental observations of sporadic aurorae is indicated by the use of a variety of descriptive terms (e.g. "lightning", "rainbow", "streak" or "grid").

There are two tentative reasons for believing that sporadic aurorae may be associated with solar activity, despite the fact that they occur under weak-to-moderate levels of geomagnetic activity. First, as noted in Sect. 3.2, there is some evidence within the interval AD 1840-1911 for recurrent, though possibly intermittent, auroral activity on a timescale almost exactly equal to the mean synodic-solar-rotation period. There is similar evidence for recurrent auroral activity at many other times during the past two millennia. For example, there is strong evidence for recurrent (but intermittent) auroral activity between about the middle of AD 1127 and the middle of AD 1129 (Willis and Stephenson, 2001). Second, Willis et al. (2006) have drawn attention to the presence of large sunspots near the central solar meridian at the times 
of modern Japanese auroral observations. Although sunspot observations are not readily available throughout the interval 1840-1911, a provisional study of the recorded sunspot measurements from Kew and Greenwich suggests that there was at least one sunspot that was both large enough to be seen with the unaided eye and reasonably close to the central solar meridian at the times of some of the East Asian auroral observations in the interval 1840-1911 (Tables 1 and 2). Therefore, the level of solar activity may possibly have been high at these particular times, even if the auroral observations are apparently associated with weak-to-moderate levels of geomagnetic activity. A detailed study of the complex association between solar, geomagnetic and auroral activity, particularly at such early times when the available information is quite primitive by modern standards, is beyond the intended scope of the present paper.

However, it is hoped that similar investigations of the auroral observations recorded by members of the Aurora Section of the British Astronomical Association will reveal more recent examples of sporadic aurorae (albeit at higher geomagnetic latitudes) that have occurred at times when detailed geomagnetic, interplanetary and solar data are available. Moreover, such auroral observations have the added advantage that they are directly comparable with the East Asian auroral observations, at least in the sense that both sets of observations were made without the aid of specialised instrumentation.

In conclusion, evidence has been found in Chinese and Japanese histories for the occurrence of sporadic aurorae in East Asia during the interval 1840-1911. Special attention has been paid to the careful translation of the oriental historical records into English, in order to extract the relevant scientific information. In particular, the recorded descriptions of the auroral displays suggest that several of the East Asian examples of sporadic aurorae are characterised by spatial structure. Silverman (2003) discussed the occurrence of sporadic auroral observations at relatively low magnetic latitudes in the United States at various times in the interval 1880-1940. However, there is a notable difference between his results and those obtained in the present investigation. Because of the configuration of the geomagnetic field during the nineteenth and twentieth centuries, magnetic latitudes are less than geographic latitudes in East Asia (Table 1), whereas magnetic latitudes are greater than geographic latitudes in the United States (Silverman, 2003). Consequently, the lowest corrected geomagnetic latitude at which the aurora was seen in East Asia, namely about $16^{\circ}$ (Guangdong Province, China, in $1863,1871,1872,1897$ and 1899 ), is very much closer to the estimated threshold magnetic latitude of approximately $15^{\circ}$ for a visual auroral event (Silverman, 1995) than are the corrected geomagnetic latitudes of the stations recording sporadic auroral observations in the United States (Silverman, 2003). Further research is required to explain how sporadic aurorae can occur at such low magnetic latitudes at times that apparently correspond to weak-to-moderate levels of geomagnetic activity.

\section{Appendix A}

\section{The East Asian auroral records}

The Chinese and Japanese records that are listed in Tables 1 and 2 are presented in this Appendix, which provides a full translation into English and a complete historical reference for all but one of these records. As noted in Sect. 2, the translations of the oriental records given in this paper provide scientific information on auroral displays observed in East Asia during the interval 1840-1911, including observations of sporadic aurorae (as defined in Sects. 1 and 3). The presentation of the East Asian auroral records largely follows the format employed by Willis et al. (2005). One minor difference, however, is that polysyllabic hanyu pinyin (rather than Wade-Giles) has been used exclusively in this paper for the romanisation of Chinese words.

Further background information on such general matters as the sources of the ancient oriental auroral observations, calendar conversions and other observational details can be found in previous papers (Willis and Stephenson, 2000; Willis et al., 2005). For completeness, however, Table A1 presents the Chinese sexagenary (60-day) cycle, with the names of the cyclical days written in hanyu pinyin. This table has been presented in Annales Geophysicae before (Willis and Stephenson, 2000; see their Table 2) but in the earlier paper the alternative Wade-Giles system of romanisation was used for the names of the cyclical days. It should also be noted here that all times quoted in the translations of the auroral records are expressed in local time (LT) and all directions are expressed in terms of the following convenient abbreviations: N, NE, E, SE, S, SW, W, NW (i.e. the points of the compass) and $\mathrm{Z}$ (i.e. the zenith).

In Chinese astronomy, the linear units chi ("feet") and zhang (equal to $10 \mathrm{chi}$ ) were often used as angular units. Investigation of recorded planetary conjunctions in which the angular separation is expressed in chi indicates that chi and $d u$ ("degrees"; 365.25 to a circle) were equivalent. Hence it may be assumed that $1 \mathrm{chi}$ was equivalent to about 1 degree (Stephenson and Green, 2004). Presumably 1 zhang was equivalent to about 10 degrees, but expressions such as "several tens of zhang" (Ref. No. 07*) may merely indicate a very large arc of sky.

The Chinese and Japanese auroral records listed in Tables 1 and 2 are translated separately in the following subsections, with the Gregorian date included in the title (in bold typeface), together with the reference number (Ref. No.), in order to identify uniquely each individual observation. The country and place of observation are given first, followed by the reign period, year, lunar month and day in the Chinese calendar (which was adopted with little change in Japan and also Korea). The full translation of each auroral record is followed by the title of the relevant oriental history (in italics) and the appropriate chapter number (if applicable) in parentheses (e.g. (Hunan tongzhi, 244)). In the single example of 
Table A1. The Chinese sexagenary cycle (with the day names written in hanyu pinyin).

\begin{tabular}{|c|c|c|c|c|c|c|c|c|c|c|c|c|}
\hline & $z i$ & chou & yin & mao & chen & $s i$ & $w u$ & wei & shen & you & $x u$ & hai \\
\hline jia & 1 & & 51 & & 41 & & 31 & & 21 & & 11 & \\
\hline$y i$ & & 2 & & 52 & & 42 & & 32 & & 22 & & 12 \\
\hline bing & 13 & & 3 & & 53 & & 43 & & 33 & & 23 & \\
\hline ding & & 14 & & 4 & & 54 & & 44 & & 34 & & 24 \\
\hline$w u$ & 25 & & 15 & & 5 & & 55 & & 45 & & 35 & \\
\hline$j i$ & & 26 & & 16 & & 6 & & 56 & & 46 & & 36 \\
\hline geng & 37 & & 27 & & 17 & & 7 & & 57 & & 47 & \\
\hline xin & & 38 & & 28 & & 18 & & 8 & & 58 & & 48 \\
\hline ren & 49 & & 39 & & 29 & & 19 & & 9 & & 59 & \\
\hline gui & & 50 & & 40 & & 30 & & 20 & & 10 & & 60 \\
\hline
\end{tabular}

a Japanese auroral observation recorded in a scientific journal, the title of the journal (in italics) and the specific volume number and year are given in parentheses (e.g. (Tenmon geppo, vol. 26, 1933)). Following the customary style of writing oriental book and journal titles, a capital letter is used only in the first word of the title (apart from place names).

In a general context, it should be noted that two of the Japanese records on 1872 February 4 (Ref. No. 30) use the terms "polar light" (kyoku hikari) and "northern light" (kita hikari) to describe the auroral display. Therefore, it seems likely that by this date some Japanese observers had an understanding of the aurora, as described in the contemporary literature from the Western world, and used what are now regarded as fairly standard terms.

\section{The auroral observation on 1844 April 21 (Ref. No. 01*)}

[China, Hunan Province] Daoguang reign period, 24th year, 3rd month, 4th day. "At dusk, in the S direction, light illuminated the sky; after about one [double] hour [ $=2 \mathrm{~h}]$ it vanished." (Hunan tongzhi, 244)

\section{The auroral observation on 1845 March 22 (Ref. No. 02)}

[Japan, Kyōto?] Kōka reign period, 2nd year, 2nd month, 15 th day. "In the zenith [i.e. in mid-sky], there was/was seen a white vapour." (Jijiroku, 2; Bunsei irai no nikki) [N.B. These two texts make no mention of night.]

\section{The auroral observation on 1849 June 2 (Ref. No. 03*)}

[China, Jiangsu Province] Daoguang reign period, 29th year, (intercalary) 4th month, day jimao (16). "At night, the sky was red like blood; suddenly there was torrential rain." (Wuyang zhi yu, 5)
The auroral observation on 1853 February 27 (Ref. No. 04*)

[China, Shanxi Province] Xianfeng reign period, 3rd year, 1st month, 20th day. "At the [double] hour yin [03:0005:00 LT], the sky was red." (Jizhou quanzhi, 7)

\section{The auroral observation on 1853 April 23 (Ref. No. 05)}

[China, Shaanxi Province] Xianfeng reign period, 3rd year, 3rd month, 16th day. "At the third watch of the night [23:0001:00 LT], the sky was red like blood." (Chongxiu Jingyang xian zhi, 2)

\section{The auroral observation on 1853 July 12 (Ref. No. 06*)}

[China, Hubei Province] Xianfeng reign period, 3rd year, 6th month, 7th day. "At the [double] hour $x u$ [19:00-21:00 LT], there were two streaks of white vapour; the centre was bluegreen while the lower part was purple (zi); one [streak] was long and one was short; they had the form of a roll of silk gauze reaching straight to the zenith. [The display] extended from the $\mathrm{S}$ to the $\mathrm{N}$, gradually twisting to the $\mathrm{W}$ and disappearing." (Zhong xiang xian zhi, 17) [N.B. The colour $z i$ is translated in different dictionaries as "purple", "blue-red" and "violet".]

\section{The auroral observation on 1853 August 12 (Ref. No. 07*)}

[China, Sichuan Province] Xianfeng reign period, 3rd year, 7th month, 8th day. "At night, there was a black (hei) vapour like a rainbow; it extended from the $\mathrm{W}$ to the $\mathrm{E}$, several tens of zhang (i.e. very many degrees) in length." (Zengxiu Guan xian zhi, 14)

\section{The auroral observation on 1855 August 23 (Ref. No. 08)}

[Japan, Tōkyō] Ansei reign period, 2nd year, 7th month (11th day). "This month in the $\mathrm{S}$ direction, below the Moon, a white vapour was seen. On the 11th day, during the night at 
the 4th hour [21:00-23:00 LT], it became especially bright." (Bukou nenpyo, 2) [N.B. The Moon was about three-quarters full on August 23.]

The auroral observation on 1856 August 18 (Ref. No. 09)

[China, Guizhou Province] Xianfeng reign period, 6th year, 7th month, 18th day. "Just at midnight, a red rainbow hung down in the NW; it was like blood [in colour]." (Lipingfu zhi, 1)

\section{The auroral observation on 1856 August 19 (Ref. No. 10)}

[China, Guizhou Province] Xianfeng reign period, 6th year, 7th month, 19th day. "At night, a red rainbow drooped down in the NW; it was like blood [in colour]." (Guzhouting zhi, 1)

\section{The auroral observation on 1859 March 2 (Ref. No. 11)}

[China, Hubei Province] Xianfeng reign period, 9th year, 1st month, 28th day. "At night, in the sky there was red vapour; it appeared divided like a grid (jing)." (Huangmei xian zhi, 37)

\section{The auroral observation on 1859 August 4 (Ref. No. 12)}

[China, Henan Province] Xianfeng reign period, 9th year, 7th month, 6th day. "At night, in the northern (kan) direction, the sky was red like fire." (Xu Yingyang xian zhi, 12)

\section{The auroral observations on 1859 September 2 (Ref. Nos. 13 and 14)}

(i) [China, Hebei Province] Xianfeng reign period, 9th year, 8th month, day guimao (40). "At night, red vapour rose at the NW; it extended to the NE; at daybreak it began to vanish." (Luancheng xian zhi, 3)

(ii) [Japan, Shingū, Wakayama Prefecture] Ansei reign period, 6th year, 8th month, 6th day. "At night, from the 6th hour [17:00-19:00 LT] to midnight, in the N direction, there was a fire disaster. It was as if red." (Koutei nendai ki) [N.B. Shingū $\left(33^{\circ} 43^{\prime} \mathrm{N}, 136^{\circ} 00^{\prime} \mathrm{E}\right)$ is on the Kii-hantō peninsula.]

The auroral observation on 1861 July 23 (Ref. No. 15)

[China, Sichuan Province] Xianfeng reign period, 11th year, 6th month, 16th day. "In the middle of the night, there was a banner in the zenith. Its colour was red; rising and falling it fluttered. Only after a long while did it vanish. Many people saw it." (Pingshan xian xuzhi, Final chapter)

\section{The auroral observation on 1862 January 1 (Ref. No. 16)}

[China, Sichuan Province] Xianfeng reign period, 11th year, 12th month, day yimao (52). "There was a split in the sky several tens of zhang (i.e. very many degrees) in length and several chi (degrees) in width; there were glittering lights, which eventually conjoined." (Xiushan xian zhi, 3)

[N.B. Not specifically stated to have occurred at night, although probably obvious in this case.]

The auroral observation on 1862 July 29 (Ref. No. 17)

[China, Shanghai Municipality] Tongzhi reign period, 1st year, 7th month, 3rd day. "In the middle of the night, the sky suddenly became bright as day. After a while it became dim." (Lou xian xuzhi, 12)

The auroral observation on 1863 January 4 (Ref. No. 18)

[China, Guangdong Province] Tongzhi reign period, 1st year, 11 th month, 15th day. "In the middle of the night, multicoloured (wu se) clouds appeared." (Raoping xian zhi, 13)

\section{The auroral observation on 1863 February 18 (Ref. No. 19*)}

[China, Hebei Province] Tongzhi reign period, 2nd year, 1st month, day wushen (45). "Red vapour appeared at the SE." (Luancheng xian zhi, 3) [N.B. Not specifically stated to have occurred at night.]

The auroral observation on 1866 August 27 (Ref. No. 20*)

[China, Shanghai Municipality and Zhejiang Province] Tongzhi reign period, 5th year, 7th month, 18th day. "Suddenly, when night had fallen, in the SE there were glittering lights above. It was like lightning but was not lightning. The shadowy clouds scattered and all the constellations disappeared; it suddenly became purple (zi) in colour. In an instant it was as black as ink and the constellations reappeared." (Chongji Fengjing xiaozhi, 10; Jiashan xian zhi, 34) [N.B. The Moon - just past full - would have risen about 40 minutes after sunset.]

\section{The auroral observation on 1866 November 5} (Ref. No. 21)

[China, Hunan Province] Tongzhi reign period, 5th year, 9th month, 28th day. "In the middle of the night, a red light extended across the sky; it was several zhang (i.e. many degrees) in width. Its light illuminated the Earth like daylight; a while later it disappeared." (Xiangyang xian zhi, 29)

\section{The auroral observation on 1868 July 6 (Ref. No. 22)}

[Japan, Tōkyō] Meiji reign period, 1st year, 5th month, 17th day. The authors have not yet been able to obtain the original text for this particular observation, despite several searches by helpful Japanese colleagues. However, Matsushita (1956) includes this observation in his list of ancient aurorae seen in Japan. From the information presented in his Table 1, it is 
possible to construct the following pseudo-translation: "At midnight, two arcs [extended across the sky] from E to W." Moreover, this auroral display was observed from Tōkyō the Japanese capital at the time. Although Matsushita classifies this observation as being "unlikely" on a fivefold classification system ranging from "certain" to "unlikely", it is retained in this study because the description suggests an auroral display rather than some other astronomical or meteorological phenomenon.

\section{The auroral observation on 1869 July 25 (Ref. No. 23)}

[China, Hubei Province] Tongzhi reign period, 8th year, 6th month, 17th day. "In the evening, there was a blue-green rainbow, which curved from the $\mathrm{E}$ to the $\mathrm{W}$; it extended across half the sky." (Huang'an xian zhi, 10)

\section{The auroral observation on 1870 February 25 (Ref. No. 24)}

[China, Jiangxi Province] Tongzhi reign period, 9th year, 1st month, 26th day. "At night, a red vapour appeared; it was divided like a grid." (Dehua xian zhi, 53)

\section{The auroral observation on 1871 February 16 (Ref. No. 25)}

[China, Shanxi Province] Tongzhi reign period, 9th year, 12th month, 27th day. "At the time of the third watch [22:5001:10 LT], the sky was red in colour; the entire Earth was as if on fire." (Jizhou quanzhi, 7)

\section{The auroral observation 1871 September 17 (Ref. No. 26)}

[China, Guangdong Province] Tongzhi reign period, 10th year, 8th month, 3rd day. "At the [double] hour chou [01:0003:00 LT] in the NE there was a streak of red light that soared upwards; it was just like daylight. At first it was red in colour but suddenly changed to yellow and then changed to green; its vapour was misty. In an instant there was torrential rain." (Jieyang xian xuzhi, 4)

\section{The auroral observation on 1872 January 10 (Ref. No. 27)}

[China, Shaanxi Province] Tongzhi reign period, 10th year, 12th month, 1st day. "In the evening, the sky was split open; in the $\mathrm{S}$ there was a pale yellow colour; the $\mathrm{N}$ was completely red." (Qian xian xinzhi, 8)

\section{The auroral observation on 1872 January 11 (Ref. No. 28)}

[China, Shanxi Province] Tongzhi reign period, 10th year, 12th month, 2nd day. "At night in the fourth watch [01:2003:50 LT], red light filled the sky, as if the Sun had risen. [It lasted] from the [double] hour chou [01:00-03:00 LT] to the [double] hour yin [03:00-05:00 LT]. After this time it gradually dispersed." (Huairen xian xinzhi, 1)
The auroral observations on 1872 February 4 (Ref. Nos. 29 and 30)

(i) [China, Hebei Province] Tongzhi reign period, 10th year, 12th month, 26th day. "At night, from the NE to the SW, the sky was red like fire; only at the sounding [by bell] of dawn did it vanish." (Dongguang xian zhi, 11)

(ii) [China, Hubei Province] Tongzhi reign period, 10th year, 12th month, 26th day. "At midnight, a red light rose in the NW and in an instant spread over the sky; when the Sun rose, it began to dissipate." (Guanghua xian zhi, 8)

(iii) [Japan, Hamada (Shimane Prefecture)] Meiji reign period, 4th year, 12 month, 26th day. "At night in the $\mathrm{N}$ direction it was like fire. In the $\mathrm{N}$ direction from above the sea to the sky a fire pillar stood, according to eyewitness(es). Night by night it became dimmer and moved slowly to and fro and finally disappeared. I presume that this was the polar light." (Annals of Hamada town) The well-known geologist Kochibe Tadyoshi obtained two separate accounts from different people: Fujii Muneo (dated 12th month, 26th day) and Masuda Reizo (dated 12th month, 28th day). These, and his own comments, Kochibe inserted in his book entitled: The earthquake disaster at Iwami in the 5th year of the Meiji reign period. These accounts are cited in (iv) and (v).

(iv) [Japan, Shimane Prefecture] "Meiji reign period, 4th year, 12 month, 26th day (author's note: below written - i.e. in a further source - as the 28th day). At night in the $\mathrm{N}$ direction it was red like fire ..." (Abstract of written note by the old man Fujii Muneo: quoted by Kochibe Tadyoshi: The earthquake disaster at Iwami in the 5th year of the Meiji reign period) [N.B. The auroral description ends after the word "fire" and continues on a separate subject. Kochibe Tadyoshi also cited further accounts from the 12th month, 28th day - see 1872 February 6.]

(v) [Japan, Shimane Prefecture?] Meiji reign period, 4th year, 12 month, 26th day. "In the year before the earthquake, 12th month, 26th day, at night in the NW sky there appeared a red coloured light, so that I could count the number of trees in the mountain forest. I presume that it was the northern light." (Imamura Akitune: The Hamada earthquake in the 5th year of the Meiji reign period) [N.B. The specific term "northern light", not "polar light", is used here.]

\section{The auroral observation on 1872 February 5 (Ref. No. 31)}

[China, Hubei Province] Tongzhi reign period, 10th year, 12th month, 27th day. "At the [double] hour chou [01:0003:00 LT], red vapour filled the sky, rising in the NE as far 
as the SW; light shone like fire. Within the cloud (yun) there was one star like a bowl; its colour was blue. After a while it began to disappear." (Jing xian zhi, 14)

\section{The auroral observations on 1872 February 6} (Ref. No. 32)

(i) [Japan, Shimane Prefecture] Meiji reign period, 4th year, 12th month, 28th day. "At night I was in the office on night duty. At around the 2 nd hour of the morning, someone shouted that there was a fire. When I got up and looked around, I saw that due E the sky was bright red like a distant fire. It did not disappear until the sky started to brighten towards the dawn." (Report by Masuda Reizo; quoted by Kochibe Tadyoshi: The earthquake disaster at Iwami in the 5th year of the Meiji reign period) [N.B. The way the time of night is expressed is precisely the way in which " 2 a.m." is expressed today.]

(ii) [Japan, Shimane Prefecture] Author's note to the previous record: "It seemed that the NE sky was as red as fire not only for one night. Moreover, although the districts [subsequently] affected by the earthquake disaster seemed to be on fire, the people living there did not see the phenomenon. Thus the people around Tsuwano in Kinoashi County thought there was a fire in the direction of Takatsu in Mino County, whereas people in Masuda thought it was in the direction of Hamada and people in Ōmori thought it was in the direction of Kiduki. Around Taisha [the Grand Shrine], it was thought that there was a great fire on Oki [islands]." (Kochibe Tadyoshi: The earthquake disaster at Iwami in the 5th year of the Meiji reign period)

(iii) [Japan, Shimane Prefecture] "Last year, the 12th month, 28th day, in the $\mathrm{N}$ sky, a fire pillar (or fire pillars) was seen. This was the festival at the end of the year. The farmers from Imohara village who were gathered in my house were shocked and returned home in haste. They later told me that flames were visible in the $\mathrm{N}$ direction from their place." (Report by Shimada and his colleagues)

(iv) [Japan, Shizuoka Prefecture] "Tanaka Masao ... in the 4th year of the Meiji reign period, 28th day ... travelled from Kōbe on the special steamer service 'Keier'. When he reached the coast at Enshu at midnight the $\mathrm{N}$ sky was bright and red." (Imamura Akitune: The Hamada earthquake in the 5th year of the Meiji reign period) [N.B. Enshu is equivalent to the present-day western part of the Shizuoka Prefecture. In this particular case, the location of the auroral observation is taken to be Hamamatsu $\left(34^{\circ} 42^{\prime} \mathrm{N}, 137^{\circ} 44^{\prime} \mathrm{E}\right)$ in Table 1 , rather than the present-day capital Shizuoka.]
The auroral observation on 1872 June 20 (Ref. No. 33)

[China, Guangdong Province] Tongzhi reign period, 11th year, 5th month, 15th day. "At night, red light filled the sky." (Raoping xian zhi, 13)

\section{The auroral observation on 1872 November 30} (Ref. No. 34*)

[China, Jiangsu Province] Tongzhi reign period, 11th year, 10th month, 30th day. "Towards evening, there was a dim light in the sky like a rainbow [stretching] from $\mathrm{W}$ to $\mathrm{E}$; its southern and northern edges were most clearly delineated." (Xijin xushi xiaolu, 1)

\section{The auroral observation on 1873 January 24 (Ref. No. 35)}

[China, Shaanxi Province] Tongzhi reign period, 11th year, 12th month, 26th day. "At night, the sky was red." (Wugong xian xuzhi, 1)

\section{The auroral observation on 1897 February 1 (Ref. No. 36)}

[China, Guangdong Province] Guangxu reign period, 22nd year, 12th month, 30th day (New Year's Eve). "At the [double] hour $x u$ [19:00-21:00 LT], red vapour suddenly appeared in the SW, about ten zhang (i.e. very many degrees) wide; its light lit up the sky." (Longshan xiang zhigao, 2; Shunde xian zhi, 23)

The auroral observation on 1899 April 8 (Ref. No. 37)

[China Guangdong Province] Guangxu reign period, 25th year, 2nd month, 28th day. "At night, red light was emitted from the sky, and was only extinguished at approximately 1.30 a.m. [01:30 LT]." (Dan xian zhi, 18) [N.B. The term translated as "1.30 a.m." is a modern expression.]

The auroral observation on 1900 January 30 (Ref. No. 38)

[China, Anhui Province] Guangxu reign period, 25th year, 12th month, 30th day (New Year's Eve). “There was a light like lightning, rising from the NW, which burnt and shone like daylight." (Huoshan xian zhi, 15)

\section{The auroral observation on 1905 January 16 (Ref. No. 39)}

[China, Shanghai City] Guangxu reign period, 30th year, 12th month, 11th day. "At midnight, a red rainbow appeared [extending] from the $\mathrm{E}$ to the $\mathrm{W}$; it was seen in the $\mathrm{N}$ direction." (Shanghai nianliubao zhi, 4)

\section{The auroral observation on 1908 July 12 (Ref. No. 40)}

[China, Shaanxi Province] Guangxu reign period, 34th year, 6th month, 14th day. "At the first watch [19:45-21:30 LT], a rainbow extended from $\mathrm{E}$ to $\mathrm{W}$; after a while, it began to disappear." (Ziyang xian zhi, 5) 
The auroral observations on 1909 September 25 and 26 (Ref. Nos. 41 and 42)

[Japan, Hokkaidō, Akita and Niigata Prefectures] Meiji reign period, 42nd year, 9th month, 25th and 26th days. "This occurrence was a famous thing, since it was visible in various areas of Hokkaidō, Akita and Niigata. It was recorded in various newspapers of the time. Mr Saweda Tanejiro's sketches from the sea towards Hakodate [Hokkaidō Prefecture] and his observations are recorded on page 132 of issue 21 of this journal." (Tenmon geppo, vol. 26, 1933). A brief translation from the Tenmon geppo (= Astronomical Herald), vol. 21, page 132, 1909 is as follows: "Saweda Tanejiro watched the phenomenon from a small boat on the sea. The phenomenon started at about 23:30 LT and ended at around 00:55 LT. He waited one or two hours after that but could not see the light any more ... The light was seen to the lower left of the Pole Star." [N.B. The observing site is specified as being close to Otobe in Hokkaidō Prefecture $\left(41^{\circ} 57^{\prime} \mathrm{N}, 140^{\circ} 08^{\prime} \mathrm{E}\right)$ and one of the sketches apparently shows rays emanating from a small region of the horizon. By this date, Western methods of timing were in vogue in Japan.]

\section{Appendix B}

\section{Implausible East Asian "auroral" records that have been rejected}

As noted in Sect. 2, two records included in the auroral database compiled by Willis et al. (2005) have been rejected in this investigation, although it must be emphasised that neither of these records was invoked in the earlier study of possible intense historical geomagnetic storms (Willis et al., 2005). The Japanese "auroral" observation on 1850 August 15 has been rejected because the quoted double hour shen (15:00-17:00 LT) corresponds to late afternoon, which is long before sunset in August. The Chinese "auroral" observation on 1885 December 26 has been rejected because the description of the phenomenon is obscure and seems more like a meteor display, despite the fact that it is included in the list compiled by the Beijing Observatory (1988). This record states "at midnight, stars filled the sky; the majority of them became comets, following each other in succession at random; there was the sound [as if] of laughter." (Yuci xian zhi, 14).

These two rejected records illustrate the impracticability of achieving anything like complete certainty when utilising historical records. A further specific example serves to highlight the particular difficulties associated with the interpretation of historical auroral records. Searches of the additional Korean historical encyclopedia Chungbo munhon pigo, which was not considered in the compilation of the auroral database discussed by Willis et al. (2005), have revealed a single example of a potential Korean auroral observation within the interval 1840-1911. This Korean record, dating from 1843 , is presented and discussed in the following paragraph, using the same format as employed in Appendix A. It is followed by a discussion of several contemporaneous Japanese observations.

\section{The "auroral" observation on 1843 March 12}

[Korea, Seoul?] King Honjong, 9th year, 2nd month, day yiyou (22). "A white vapour was seen in the W direction." (Chungbo munhon pigo, 8)

The Korean text makes no mention of night but Matsushita (1956) lists an imprecisely dated Japanese auroral observation in 1843 , which refers to a white vapour in the W or WNW direction that was observed from Edo (Tōkyō) for about 2 weeks up to March 14 at about 20:00 LT. Although there are five independent Japanese reports, Matsushita (1956) classified this auroral observation as being "unlikely" on a fivefold reliability classification system ranging from "certain" to "unlikely".

The five independent Japanese records may be translated as follows:

(i) [Japan, Tōkyō] Tempo reign period, 14th year, 2nd month, 6th day. "From the night of the 6th day [1843 March 6], for several nights in the SW direction, a white rainbow appeared." (Bukou nenpyo)

(ii) [Japan, Tōkyō] Tempo reign period, 14th year, 2nd month, 6th day. "From the middle decade of the 1st month there was a white vapour in the W direction. Every early evening it was visible but it disappeared at the end of the 2nd month. In the Suruga-wan [bay] area it is said that it appeared in the direction of Tokuganji [temple] on the opposite side of the Abe-gawa [river]." (Takee nenpyo hosho ryaku)

(iii) [Japan, Tōkyō] Tempo reign period, 14th year, 2nd month, 6th day. "In this month there was a white vapour in the WSW direction." (Zoku tokugana jikki)

(iv) [Japan, Tōkyō] Tempo reign period, 14th year, 2nd month, 6th day. "From the first decade of the 2nd month onwards a white vapour appeared in the evening in the WSW direction. Its form was like a long cloth, several tens of $j \bar{o}$ [in length: $j \bar{o}=$ zhang]. After the hour jutsu [19:00-21:00 LT] it disappeared. From the 10th day, because the weather was not stable, it was difficult to make it out. On the nights of the 13th and 14th days, the white vapour that had been visible gradually thinned out." (Gyokurai zakki)

(v) [Japan, Tōkyō] Tempo reign period, 14th year, 2nd month, 6th day. "From the 4th to the 5th days, a white vapour appeared in the direction of Kōfu [W of Tōkyō in Yamanashi Prefecture]." (Zoku taihei nenpyo) 
There is general agreement between the Japanese and Korean records, at least in the sense that a white vapour was seen in a westerly direction (although Matsushita quotes WNW rather than WSW). However, the Japanese records suggest that the phenomenon existed for up to six weeks (particularly the second record), which is a most unlikely duration for an auroral display. In addition, many Chinese and also Japanese records refer to an object described as either a "broom star" or a "long star", which was seen from early March until May. This terminology suggests that all these particular East Asian observations of a white vapour actually refer to a comet rather than an auroral display. Therefore, the exactly dated Korean "auroral" observation on 1843 March 12 is rejected in this study. [N.B. European records report a brilliant daylight comet in the spring of 1843. From the various records compiled by Kronk (2003), this comet was first sighted on February 6 and finally lost to view on April 19.]

Acknowledgements. Values of the magnetic indices ( $A k$ and $a a$ ) were obtained from the World Data Centre for Solar-Terrestrial Physics at the Rutherford Appleton Laboratory. The corrected geomagnetic co-ordinates presented in Table 1 have been obtained from the Space Physics Data Facility/Modelweb software, made available to the scientific community by the Goddard Space Flight Center (http://modelweb.gsfc.nasa.gov). The authors thank D. F. Starr, K. Tanikawa, J. P. C. Moffett and P. R. Dimelow for help with the translation and interpretation of records written in Classical Chinese and Japanese. They also thank D. W. Hughes and S. Silverman for constructive and helpful comments. F. R. Stephenson acknowledges with sincere thanks the award of a Leverhulme Emeritus Fellowship. Part of the research reported in this paper was undertaken while Huiping Fang, then an undergraduate in the Department of Physics at the University of Warwick, was in receipt of a Student Bursary from the Royal Astronomical Society, which is gratefully acknowledged.

Topical Editor M. Pinnock thanks S. Silverman and D. W. Hughes for their help in evaluating this paper.

\section{References}

Abbe, C.: An aurora in South Carolina and Kentucky, Mon. Wea. Rev., 23, 297-298, 1895.

Beijing Observatory (Eds.): Zhongguo gudai tianxiang jilu zongji (A Union Table of Ancient Chinese Records of Celestial Phenomena) (In Chinese), Jiangsu Kexue Jishu Chubanshe, Nanjing, pp. 27-60, 1988.

Botley, C. M.: Sporadic aurora, Planet Space Sci., 11, 723-724, 1963.

Davis, T. N.: Observed microstructure of auroral forms, J. Geomagn. Geoelctr., 30, 371-380, 1978.

Davis, T. N.: The Aurora Watcher's Handbook, University of Alaska Press, Fairbanks, Alaska, 1992.

Eddie, L. A.: Note on an auroral display, J. Brit. Astron. Assn., 4, 381,1894

Fritz, H.: Verzeichniss Beobachteter Polarlichter, C. Gerold's Sohn, Wien, 1873.

Fritz, H.: Das Polarlicht, F. A. Brockhaus, Leipzig, 1881.
Kamide, Y.: What is an "Intense Geomagnetic Storm"?, Space Weather, 4, S06008, doi:10.1029/2006SW000248, 2006.

Kronk, G. W.: Cometography: A Catalog of Comets, Volume 2: 1800-1899, Cambridge University Press, Cambridge, 2003.

Loomis, E.: The great auroral exhibition of August 28th to September 4th, 1859, American Journal of Science and Arts (Second Series), vol. XXVIII, 385-408, 1859; Ibid. vol. XXIX, 92-97, 249266, 386-399, 1860; Ibid. vol. XXX, 79-100, 339-361, 1860; Ibid. vol. XXXII, 71-84, 318-335, 1861.

Matsushita, S.: Ancient aurorae seen in Japan, J. Geophys. Res., 61, 297-302, 1956.

Mayaud, P. N.: A hundred year series of geomagnetic data, 18681967, indices $a a$, Storm sudden commencements, IAGA Bulletin No. 33, IUGG Publications Office, Paris, 1973.

Mayaud, P. N.: Derivation, Meaning, and Use of Geomagnetic Indices, Geophysical Monograph 22, American Geophysical Union, Washington, D.C., 1980.

Nevanlinna, H. and Kataja, E.: An extension of the geomagnetic activity index series $a a$ for two solar cycles (1844-1868), Geophys. Res. Lett., 20, 2703-2706, 1993.

Nevanlinna, H. and Ketola, A.: Magnetic results from Helsinki magnetic-meteorological observatory. Part III: Declination 1854-1880. Geomagnetic activity 1844-1880, Finn. Meteorol. Inst.-Geophys. Publ., 33, 1993.

Nevanlinna, H., Ketola, A., Häkkinen, L., Viljanen, A., and Ivory, K.: Geomagnetic activity during solar cycle 9 (1844-1856), Geophys. Res. Lett., 20, 743-746, 1993.

Newell, P. T., Greenwald, R. A., and Ruohoniemi, J. M.: The role of the ionosphere in aurora and space weather, Rev. Geophys., 39, 137-149, 2001.

Osaki, S.: Kinsei Nihon temmon shiryou (Pre-Modern Japanese Historical Records of Celestial Phenomena) (in Japanese), Hara Shobou, Tokyo, 1994.

Royal Greenwich Observatory: Sunspot and Geomagnetic-Storm Data Derived from Greenwich Observations, 1874-1954, H. M. Stationery Office, London, 1955.

Shiokawa, K., Ogawa, T., and Kamide, Y.: Low-latitude auroras observed in Japan: 1999-2004, J. Geophys. Res., 110, A05202, doi:10.1029/2004JA010706, 2005.

Silverman, S. M.: Low-latitude auroras: the storm of 25 September 1909, J. Atmos. Terr. Phys., 57, 673-685, 1995.

Silverman, S. M.: Sporadic auroras, J. Geophys. Res., 108, 8011, doi:10.1029/2002JA009335, 2003.

Silverman, S. M.: Comparison of the aurora of September 1/2, 1859 with other great auroras, Adv. Space Res., 38, 136-144, 2006.

Stephenson, F. R. and Green, D. A.: Historical Supernovae and their Remnants, Oxford University Press, Oxford, 2002.

The Times Comprehensive Atlas of the World: Tenth (Millennium) Edition, Times Books Group Ltd, London, 1999.

Tinsley, B. A., Rohrbaugh, R. P., Rassoul, H., Barker, E. S., Cochran, A. L., Cochran, W. D., Wills, B. J., Wills, D. W., and Slater, D.: Spectral characteristics of two types of low latitude aurorae, Geophys. Res. Lett., 11, 572-575, 1984.

Willis, D. M. and Stephenson, F. R.: Simultaneous auroral observations described in the historical records of China, Japan and Korea from ancient times to AD 1700, Ann. Geophys., 18, 1-10, 2000 , http://www.ann-geophys.net/18/1/2000/.

Willis, D. M. and Stephenson, F. R.: Solar and auroral evidence for 
an intense recurrent geomagnetic storm during December in AD 1128, Ann. Geophys., 19, 289-302, 2001,

http://www.ann-geophys.net/19/289/2001/

Willis, D. M., Armstrong, G. M., Ault, C. E., and Stephenson, F. R.: Identification of possible intense historical geomagnetic storms using combined sunspot and auroral observations from East Asia, Ann. Geophys., 23, 945-971, 2005,

http://www.ann-geophys.net/23/945/2005/.
Willis, D. M., Henwood, R., and Stephenson, F. R.: The presence of large sunspots near the central solar meridian at the times of modern Japanese auroral observations, Ann. Geophys., 24, 2743-2758, 2006, http://www.ann-geophys.net/24/2743/2006/.

Yau, K. K. C., Stephenson, F. R., and Willis, D. M.: A Catalogue of Auroral Observations from China, Korea and Japan (193 BCAD 1770), Rutherford Appleton Laboratory Technical Report RAL-TR-95-073, December 1995. 